\title{
Reducing variability in OSL rock surface dating profiles.
}

\author{
Joanne Elkadi ${ }^{\mathrm{a},{ }^{*}}$, Georgina E. King ${ }^{\mathrm{a}}$, Benjamin Lehmann ${ }^{\mathrm{b}}$ and Frédéric Herman ${ }^{\mathrm{a}}$ \\ ${ }^{a}$ Institute of Earth Surface Dynamics, University of Lausanne, 1012 Lausanne, Switzerland \\ b Laboratoire EDYTEM, Université Savoire Mont Blanc-CNRS, 73376 Le Bourget-du-Lac, France \\ *Corresponding author: joanne.elkadi@unil.ch
}

6

\section{Abstract}

In recent years, rock surface dating has seen the emergence of a technique based on optically stimulated luminescence (OSL). This application translates the depth of OSL signal bleaching within a rock surface into an exposure age or erosion rate at $1-10^{4}$ a timescales. Considerable effort has been undertaken to improve our understanding of OSL rock surface dating, yet a large amount of uncertainty associated with the method remains. Specifically, OSL profiles measured into rock surfaces can be highly scattered. Potential causes of this scatter could be lithological heterogeneity that modify bleaching rate throughout the rock, variability in surface erosion or experimental artefacts. Here, we report experiments that were conducted to explore whether experimental artefacts could contribute to the scatter in OSL profiles measured from rock surfaces exposed in Zermatt, Switzerland. This was done by varying the following parameters: (i) heating rate, (ii) isothermal holding time, (iii) luminescence signal detection filters, (iv) the sequential order of optical stimulations, and (v) core diameter. Our results indicate that sample temperature, for both preheating and stimulation, may exert a strong influence on the OSL profiles obtained. Thermal lag, i.e. the temporal offset between sample temperature and the instrument temperature, can be significant for rock slices if a heating rate of $5{ }^{\circ} \mathrm{C} \mathrm{s}^{-1}$ is used and if rock slices are placed directly on the instrument carousel. To reduce this effect, our results suggest future studies place samples in metal cups, reduce the heating 
This manuscript is a pre-print and has been submitted for publication in Quaternary Geochronology

26 rate and increase preheating and holding times prior to optical stimulation, to allow samples to

27 heat at the desired rate and reach the required temperatures.

28

29 Keywords:

30 OSL surface exposure dating

31 Heating rate

32 Gorner glacier

33 Luminescence depth profiles 


\section{This manuscript is a pre-print and has been submitted for publication in Quaternary Geochronology}

\section{Introduction}

Optically stimulated luminescence (OSL) dating is a trapped charge dating technique that measures the intensity of light emitted from a mineral (e.g. quartz or feldspar) following stimulation by light (Huntley et al., 1989; Aitken, 1998). The method is widely used and has traditionally been applied to the dating of sedimentary deposits (e.g. Rhodes, 2011), but has also recently shown a strong potential for rock surface dating applications (e.g. Sohbati et al., $2011 ; 2012 a)$.

OSL rock surface dating hinges on the principle that the energy of photons emitted by the sun is sufficient to reset the luminescence signal in minerals at the surface of the Earth. This phenomenon is termed "bleaching". Research has shown that this bleaching effect decreases with depth into a rock surface (Habermann et al., 2000; Polikreti et al., 2002; 2003; Laskaris and Liritzis, 2011), due to attenuation of the photon flux, until it eventually becomes negligible. Studies have also suggested a link between exposure time and the depth of bleaching- where the longer a surface has been exposed to daylight, the deeper into the rock surface the luminescence signal is bleached (Habermann et al., 2000; Polikreti et al., 2002; Laskaris and Liritzis, 2011; Sohbati et al., 2011; 2012a; Lehmann et al., 2018; Gliganic et al., 2019). Thus, after calibration, the luminescence bleaching profile beneath a rock surface may be used to obtain information regarding the surface's exposure history. At present, OSL rock surface dating can be applied either to determine surface exposure (e.g. Lehmann et al., 2018) or surface burial (e.g. Simms et al., 2011; Jenkins et al., 2018).

A major advantage of OSL rock surface dating is that it complements cosmogenic nuclide surface exposure dating (e.g. using ${ }^{10} \mathrm{Be},{ }^{14} \mathrm{C}$ ). For surfaces that have experienced minimal 


\section{This manuscript is a pre-print and has been submitted for publication in Quaternary Geochronology}

erosion, the luminescence profiles with depth can provide exposure ages on time scales of $10^{0}$ $10^{4} \mathrm{a}$, compared to cosmogenic nuclide dating which resolves time scales of the order $10^{3}-10^{6}$ a. OSL rock surface dating has already been successfully used in a variety of different applications, including archaeological settings (e.g. Chapot et al., 2012; Liritzis and Vafiadou., 2015; Sohbati et al., 2015) as well as relative sea level (Simms et al., 2011; Simkins et al., 2013), paleo ice sheet (Simms et al., 2012; Jenkins et al., 2018) and Alpine glacier (Lehmann et al., 2018; 2019;2020) reconstructions. On the other hand, for surfaces that have experienced considerable erosion which affects their apparent exposure age (e.g. Lehmann et al., 2019 showed that a $4 \mathrm{~mm} \mathrm{a}^{-1}$ erosion rate over the last 344 years could alter an exposure age by 930\%), OSL rock surface dating can be used to calculate erosion rates (Sohbati et al., 2018, Lehmann et al., 2019).

Despite significant advancements over the past years, luminescence-depth bleaching profiles are unfortunately often highly scattered and the cause of this scatter remains unexplained; potential sources include: (1) lithological variations within a rock surface that subsequently influence light penetration, (2) variability in surface erosion affecting the apparent bleaching depths in luminescence profiles or (3) experimental artefacts. Various studies investigating the effects of lithology (Meyer et al., 2018; Ou et al., 2018) and erosion (Sohbati et al., 2018; Lehmann et al., 2019) on luminescence profiles have been carried out, yet none have addressed the influence of experimental artefacts. In this study, we explore the latter point. To do this, we ran four experiments on bedrock samples collected from Zermatt, Switzerland, in which we varied several parameters from the measurement protocol. 


\section{2. Rock Surface Dating}

\subsection{Previous rock surface dating studies and their respective measurement parameters}

87

Since its initial use in the dating of archaeological settings through the bleaching of thermoluminescence (TL) signals (e.g. Liritzis, 1994; Richards, 1994; Theocaris et al., 1997), rock surface dating has expanded to include a variety of applications, and shifted its focus to measuring Infrared Stimulated Luminescence (IRSL) and Optically Stimulated Luminescence (OSL) signals from feldspar and quartz, respectively.

Recent rock surface dating studies have predominantly focused on the measurement of IRSL and OSL signals from multi-mineral rock slices. Table 1 summarises these studies and emphasises the variations in protocol parameters, such as the heating conditions and the placement of slices on the carousel during measurement using Risø readers. This compilation does not include rock surface dating studies that involved the measurement of grains from mineral separates instead of whole slices (Chapot et al., 2012; Sohbati et al., 2012a; al

100 Khasawneh et al., 2018; Gliganic et al., 2019).

101

2.2 Components involved in rock surface dating measurement protocols

104 As indicated in Table 1, during measurement slices can either be placed directly on a carousel or in stainless steel cups. This is usually dependent on the size and shape of the slices.

107 A standard measurement protocol for measuring the OSL signal of a rock slice follows that of 108 the well-established SAR protocol (Murray and Wintle, 2000), and begins with a preheat 


\section{This manuscript is a pre-print and has been submitted for publication in Quaternary Geochronology}

treatment where the slice is heated to an assigned temperature (e.g. $250^{\circ} \mathrm{C}$ ) with no light stimulation. This process removes short-lived and unwanted electrons that accumulate in traps of low activation energy and are unstable at room temperature (e.g. Aitken, 1985; 1998; Murray and Wintle, 2000). Once this temperature is attained, the sample is then held for a designated amount of time - termed the preheat isothermal hold. It is assumed that all shallow electron traps have been emptied by the end of the preheat (e.g. Murray and Wintle, 2000). The heating rate and isothermal holding time for a preheat can vary and, in dating studies, it is imperative to choose appropriate values as incorrect values may cause inefficient heating of the sample due to rocks' low thermal diffusivity (0.6 to $1.9 \mathrm{~mm}^{2} \mathrm{~s}^{-1}$; Drury, 1987). Any remaining electrons can potentially contribute to subsequent luminescence measurements (Aitken, 1998). If thermal treatments are not reproducible between measurement cycles, and the degree of thermal lag varies between slices, then this inter-slice heating variability could result in scatter in the data. We are able to monitor the thermal treatment experienced by the sample by recording the TL signal emitted during the preheat in a sequence.

Following the preheat, slices are optically stimulated to measure their OSL signal. To do this, the sample is heated to a fixed temperature and held for a specified time duration prior to switching on the diodes. Samples are measured at elevated temperature to ensure that unstable traps potentially populated by thermal transfer during the preheat do not contribute to the measured OSL signal. As with a preheat, the heating rate and pre-stimulation isothermal hold can be altered to ensure that the samples reach the required temperature in a uniform manner. If a sample is heated too rapidly, or not held at temperature for a sufficient amount of time, we risk producing misleading OSL results due to inter-slice heating variability mentioned previously. As a result, scatter would be observed in the data, but the effect of this can be minimised by choosing the correct measurement parameters. Thermal assistance is particularly 


\section{This manuscript is a pre-print and has been submitted for publication in Quaternary Geochronology}

134 key for the measurement of feldspar IRSL, emphasising the need for accurate and reproducible

135 thermal measurement conditions (e.g. Hütt et al., 1988).

136

137 Most modern luminescence readers are semi-automated, and the different thermal and optical

138 treatments and irradiations of a given measurement sequence are programmed for the

139 instrument using software such as Sequence Editor. Whilst we program a desired final

140 temperature for any thermal treatment, it is generally difficult to monitor the exact heating rate

141 and temperature that the sample experiences during measurement. In contrast, it is possible to

142 predict when trapped charge will be evicted from a mineral using the kinetic parameters that

143 describe a particular luminescence signal's thermal stability. Generally, lower heating rates

144 result in the equivalent trapped charge being evicted at lower temperatures and the converse is

145 also true (e.g. Schmidt et al., 2018). For example, quartz has a well characterised TL peak at

$146 \sim 100{ }^{\circ} \mathrm{C}$, termed the ' $110{ }^{\circ} \mathrm{C}$ peak', when heated at $5{ }^{\circ} \mathrm{C} \mathrm{s}^{-1}$ (Bailey, 2001), however the peak

147 position varies depending on the heating rate of the sample. We can use the position of the 110

$148{ }^{\circ} \mathrm{C}$ peak in a TL curve from a preheat to approximate a sample's thermal pretreatment (Duller

149 et al., 2020), and in particular a sample's heating rate. 
This manuscript is a pre-print and has been submitted for publication in Quaternary Geochronology

\begin{tabular}{|c|c|c|c|c|c|c|c|c|c|}
\hline \multirow[b]{2}{*}{ Citation } & \multirow{2}{*}{$\begin{array}{c}\text { Dating } \\
\text { application }\end{array}$} & \multirow{2}{*}{$\begin{array}{c}\text { Core } \\
\text { diameter } \\
(\mathrm{mm})\end{array}$} & \multirow{2}{*}{$\begin{array}{l}\text { Target } \\
\text { mineral }\end{array}$} & \multirow{2}{*}{$\begin{array}{l}\text { Detection } \\
\text { filter }\end{array}$} & \multicolumn{2}{|c|}{ Preheat } & \multicolumn{2}{|c|}{ Stimulation } & \multirow{2}{*}{$\begin{array}{l}\text { Slices resting in } \\
\text { cups or directly } \\
\text { on carousel? }\end{array}$} \\
\hline & & & & & $\begin{array}{l}\text { Heating rate } \\
\left({ }^{\circ} \mathrm{C} \mathrm{s}^{-1}\right)\end{array}$ & $\begin{array}{c}\text { Isothermal } \\
\text { hold (s) }\end{array}$ & $\begin{array}{l}\text { Heating rate } \\
\left({ }^{\circ} \mathrm{C} \mathrm{s}^{-1}\right)\end{array}$ & $\begin{array}{c}\text { Isothermal } \\
\text { hold (s) }\end{array}$ & \\
\hline Feathers et al., 2019 & Burial & 10 & Fsp & (d) & \multicolumn{4}{|c|}{-} & Cups \\
\hline Freisleben et al., 2015 & Burial & $\sim 10$ & Fsp & (a) & \multicolumn{4}{|c|}{-} & - \\
\hline Jenkins et al., 2018 & Burial & $\sim 8$ & Fsp & (b) & 1 & 100 & 1 & 100 & Cups \\
\hline Lehmann et al., 2018 & Exposure & $\sim 10$ & Fsp & (d) & 5 & 60 & 5 & 5 & Carousel \\
\hline Lehmann et al., 2019 & Exposure & $\sim 10$ & Fsp & (d) & 5 & 60 & 5 & 5 & Carousel \\
\hline Liu et al., 2019 & Exposure & $\sim 10$ & Fsp & (a) & - & 100 & - & 30 & - \\
\hline Luo et al., 2018 & Exposure & $\sim 10$ & Fsp & (d) & - & 100 & 5 & 30 & - \\
\hline Meyer et al., 2018 & Exposure & $\sim 8$ & $\begin{array}{c}\text { Qtz and } \\
\text { Fsp }\end{array}$ & $\begin{array}{l}\text { (e) for Qtz } \\
\text { (c) for Fsp } \\
\end{array}$ & 5 & - & 5 & 14 & Carousel \\
\hline Ou et al., 2018 & Exposure & $\sim 7$ & Fsp & (b) & 1 & 100 & 1 & 100 & Cups \\
\hline Rades et al., 2018 & Burial & $\sim 10$ & Fsp & (c) & - & 100 & - & - & - \\
\hline Sohbati et al., 2011 & Exposure & $\sim 10$ & Fsp & (c) & - & 60 & - & 30 & Carousel \\
\hline Sohbati et al., 2012b & Burial & 10 & Qtz & (f) & 5 & 100 & 5 & 100 & Carousel \\
\hline Sohbati et al., 2015 & Burial & $\sim 10$ & Fsp & (a) & 5 & 60 & 5 & 30 & Carousel \\
\hline Sohbati et al., 2018 & Exposure & 10 & Fsp & (a) & - & 100 & - & 30 & - \\
\hline Souza et al., 2019 & Burial & $\sim 10$ & Fsp & (a) & - & 100 & - & 30 & Carousel \\
\hline
\end{tabular}

Table 1: Compilation of previous rock surface dating studies. Fsp and Qtz denote feldspar and quartz respectively. With regards to the filters, (a) $=$

151 Schott BG-39/Corning 7-59 (2 and 4 mm respectively), (b) = Schott BG-39/Corning 7-59 (2 mm each), (c) = Schott BG-39/ Corning 7-59 (unspecified 


\section{Methodology}

\subsection{Sample preparation}

158 The two samples mentioned in this study, GG17-05-01 and GG18-05-01, are both schists from the same sample site. They were collected as part of a suite of samples in October 2018 from

160 the mountainside adjacent to the Gorner glacier, located close to the village of Zermatt,

161 Switzerland. Sample GG17-05-01 was extracted from a surface with an unknown exposure 162 age, and GG18-05-01 was collected from a surface that had been exposed during sampling of GG17-05-01 the previous year, so has a well-constrained exposure age of 342 days.

The samples were taken from bedrock using a combination of a hammer, chisel and Husqvarna K760 power cutter with a diamond blade. They were collected as $\approx 15 \mathrm{~cm} \times 15 \mathrm{~cm} \times 10 \mathrm{~cm}$ dimension blocks and immediately placed into black, light obstructing bags. In the laboratory, the blocks were then drilled using a water-cooled Husqvarna DM220 drill to extract cores of either $5 \mathrm{~mm}$ or $10 \mathrm{~mm}$ diameter. Generally, smaller diameter cores of this lithology break more easily during drilling, and extracting intact cores can be tedious and time consuming without the guarantee of a successful result. It was therefore necessary to drill multiple cores for every core successfully extracted. To avoid any potential signal resetting that may have occurred during fieldwork, the cores were drilled in the centre of the block and as far from the block edge as possible. These cores were then cut into slices using a BUEHLER Isomet low speed saw, mounted with a $0.3 \mathrm{~mm}$ thick diamond blade in the presence of a lubricant. The exact thickness of each slice was measured using a TESA Digitcal caliper, and the final average

177 thicknesses ranged from 0.32 to $1.11 \mathrm{~mm}$. All laboratory work was done under subdued redlight conditions. 


\section{This manuscript is a pre-print and has been submitted for publication in Quaternary Geochronology}

\subsection{Measurement protocols}

181

182 To investigate the influence of experimental artefacts on the scatter in luminescence profiles,

183 we focused on changing the following parameters: (i) heating rate, (ii) preheat and pre184 stimulation isothermal holding times, (iii) luminescence signal detection filters, (iv) order of optical stimulations, and (v) core diameter. This was done across four experiments - A, B, C and D - and each experiment contained three parts (Part i, ii and iii). A summary of the different

187 experimental protocols can be found in Table 2, and these are elaborated on in Tables S1-S4

188 in the Supplementary Material.

190 All experiments were performed on three $5 \mathrm{~mm}$ diameter slices and three $10 \mathrm{~mm}$ diameter

191 slices from Sample GG18-05-01. The slices had been depleted of their natural signal using 192 measurement protocol $\mathrm{Ai}$, with the $5 \mathrm{~mm}$ diameter slices placed in stainless steel cups and the

$19310 \mathrm{~mm}$ diameter slices resting directly on the carousel. The average thickness of the slices used 194 in these experiments ranges from 0.59 to $0.62 \mathrm{~mm}$ for the $10 \mathrm{~mm}$ diameter slices and from 0.57 to $0.58 \mathrm{~mm}$ for the $5 \mathrm{~mm}$ diameter slices. For both diameter types, the slices were measured without any additional mineral separation, and so were composed of an amalgamation of several minerals. Due to this, the measurement protocols included IRSL $50, \mathrm{OSL}_{125}$ and post-IR

198 IRSL $_{225}$ stimulations, with the optimum sequence order and filter combinations explored as an 199 aspect of the experiments in this study. The recent instrumentation development of a DASH reader head allows for filter combinations to be changed throughout a measurement sequence

201 (Lapp et al., 2015) and tailored to the target mineral's emission. Measuring multiple 202 luminescence signals, and thus different minerals and traps with varying bleaching 203 characteristics, allows us to obtain a maximum amount of information from samples. However, 


\section{This manuscript is a pre-print and has been submitted for publication in Quaternary Geochronology}

204

205

206

207

208

209

210

211

212

213

214

215

216

217

218

219

220

221

222

223

224

225

226

227

228

as feldspar is also responsive to blue light stimulation, it is unlikely that we are able to isolate a pure quartz signal. Nevertheless, combining IRSL and OSL luminescence signals to extract information from samples has been successfully investigated previously for both sediments and rock slices (e.g. Reimann et al., 2015, Meyer et al., 2018). With the exception of natural luminescence signals, measurements were made in response to a given regenerative dose of $51.75 \mathrm{~Gy}$ and a test dose of $51.75 \mathrm{~Gy}$. The samples were stimulated for $200 \mathrm{~s}$ and the luminescence signals for all measurements were integrated over the first $10.8 \mathrm{~s}$ of stimulation, with a background signal taken from the final $57.7 \mathrm{~s}$ of stimulation.

Measurements of the natural signal, for the reconstruction of luminescence depth profiles, were made on several cores from samples GG17-05-01 and GG18-05-01. Experimental protocol Ai was initially used on three cores, each with a diameter of $10 \mathrm{~mm}$, from sample GG18-05-01 to generate preliminary results. After analysing the results using this protocol, it was decided to undertake the experiments in this study and subsequently three cores from the same sample were taken and measured using protocol Biii, using a combination of $5 \mathrm{~mm}$ diameter slices and broken fragments from $10 \mathrm{~mm}$ diameter slices. Each core was composed of 24 slices, with the protocol Ai slices resting directly on the carousel and protocol Biii slices sat in stainless steel cups on the carousel. Slices from these cores were subsequently used in the experiments discussed above. Both protocols were also used to measure cores from GG17-05-01, for the purpose of exposure age calculations which are elaborated on in Section 6.1.

\subsection{Measurements}

All experimental measurements were carried out on a Risø TL/OSL-DA-20 luminescence reader (Bøtter-Jensen et al., 2010), ID Number 396, equipped with a DASH head (Lapp et al., 
2292015 ) and a ${ }^{90} \mathrm{Sr} /{ }^{90} \mathrm{Y}$ beta source at the University of Lausanne, Switzerland. The reader had a

230 dose rate of $0.207 \pm 0.005 \mathrm{~Gy} \mathrm{~s}^{-1}$ calibrated to gamma irradiated quartz slices resting on the

231 measurement carousel and yields a dose rate 11.4\% lower than for coarse grained quartz. Its

232 instrument reproducibility is $\sim 1.8 \%$. The measurements of the natural signal from samples

233 GG17-05-01 and GG18-05-01 were carried out using a combination of the aforementioned

234 Risø reader, in addition to two Risø TL/OSL-DA-20 luminescence readers (Bøtter-Jensen et 235 al., 2010).

237 All stimulations done at a temperature greater than $200{ }^{\circ} \mathrm{C}$ were carried out under a nitrogen 238 atmosphere.

\subsection{Instrument behaviour}

242 Independent thermocouple measurements were performed to assess the behaviour of the

243 TL/OSL-DA-20 luminescence reader ID Number 396 (Bøtter-Jensen et al., 2010) used for the

244 experiments in this study. Various temperatures were prescribed to the reader using the

245 Sequence Control software and, using a thermocouple tip soldered to a stainless steel measurement cup, the corresponding actual thermocouple temperature was measured using a

247 multimeter. The results are shown in Table 3. Across the range of temperatures used in the

248 experimental measurement protocols of this study (Table 2), we see a maximum deviation of

$2498{ }^{\circ} \mathrm{C}$ between the measured and prescribed temperatures for the temperature range up to 300

$250{ }^{\circ} \mathrm{C}$, thus confirming the reader's sample holder is reaching temperature within this tolerance.

\begin{tabular}{ccccccccccc}
\hline $\begin{array}{c}\text { Prescribed } \\
\text { temperature }\left({ }^{\circ} \mathrm{C}\right)\end{array}$ & 50 & 75 & 100 & 125 & 150 & 175 & 200 & 225 & 250 & 300 \\
\hline $\begin{array}{c}\text { Measured } \\
\text { temperature }\left({ }^{\circ} \mathrm{C}\right)\end{array}$ & 50 & 76 & 99 & 120 & 145 & 170 & 192 & 221 & 245 & 295 \\
\hline
\end{tabular}




\section{This manuscript is a pre-print and has been submitted for publication in Quaternary Geochronology}

Table 3: Results from independent thermocouple measurements on the Risø reader to confirm instrument behaviour.

\subsection{Modelling TL curves}

As mentioned in Section 2.2, for the Risø TL/OSL-DA-20 instruments used in these experiments, no measurement of actual sample temperature is possible once a sequence is launched. Since the rock slices were composed of a mixture of minerals, including quartz, the general kinetic model of quartz from Bailey (2001) implemented in the R-package 'RLumModel' (Friedrich et al., 2016) was used to predict the position of the $110^{\circ} \mathrm{C}$ peak in quartz as a function of the prescribed heating rate. The model has an electron trap depth of 0.97 $\mathrm{eV}$ and a frequency factor of $5 \times 10^{12} \mathrm{~s}^{-1}$. The $110^{\circ} \mathrm{C}$ peak was chosen as it is believed to follow a first order kinetic behaviour (e.g. Pagonis et al., 2003) and is ubiquitous in quartz samples. Once the theoretical $110^{\circ} \mathrm{C}$ peak position was calculated using the chosen model, it could then be compared to the experimental peak positions generated by the rock slices during measurement to provide information on their heating.

\section{Results}

\subsection{Natural samples}

The resultant luminescence profiles with depth for the natural signal of sample GG18-05-01 measured using protocols $\mathrm{Ai}$ and Biii, along with their corresponding model plots and chisquare goodness of fit $\left(\chi^{2}\right)$ values, are shown in Figure 1. Protocol Ai was applied to $10 \mathrm{~mm}$ diameter slices resting directly on the carousel and used U340 filters for every stimulation, whereas protocol Biii was applied to a combination of $5 \mathrm{~mm}$ diameter slices and broken 


\section{This manuscript is a pre-print and has been submitted for publication in Quaternary Geochronology}

fragments of $10 \mathrm{~mm}$ diameter slices resting in stainless steel cups on the carousel, and used a combination of U340 and BG39+BG3 filters depending on the target mineral (see Table 2).

The IRSL $\mathrm{I}_{50}$ absolute signal counts from slices measured using protocol Biii were, on average, one or two orders of magnitude lower than their corresponding measurements using protocol Ai. In each case, the luminescence signal has been normalised to the average value of the plateau, which is determined qualitatively once the luminescence signals are no longer increasing with depth. For the noisy post-IR IRSL 225 Experiment Ai profile, normalisation was done by taking an average of all the measurement points. By visually analysing the depth profiles across all three signals, it is immediately clear that the measurements made using protocol Biii generate depth profiles that are much less scattered than those measured using protocol Ai, particularly for the feldspar IRSL signals. This is further confirmed by the $\chi^{2}$ values, which improve across all three signals for protocol Biii - even in the case of the $\mathrm{OSL}_{125}$ signal which initially visually does not appear to show any reduction in scatter.

Figure 2 displays the TL plots generated during the natural $\left(L_{\mathrm{n}}\right)$ and test dose $\left(T_{n}\right)$ measurements of the GG18-05-01 natural signal slices in Figure 1. For both the $L_{n}$ and $T_{n}$ measurements, the TL curves generated using the Experiment Ai protocol exhibit large differences in their peak positions. The $T_{n}$ curves show less variation than the $L_{n}$ curves, with peak signal intensities occurring closer to when the heating plate attains its maximum temperature, whereas the $L_{n}$ curves peak at, or later than, the heating plate reaching its maximum temperature. In contrast, the TL curves for Experiment Biii reveal smaller discrepancies in their peak positions for both the $L_{n}$ and $T_{n}$ measurements. Overall the Experiment Biii TL curves peak earlier than their Experiment Ai counterparts for both the $L_{n}$ and $T_{n}$ measurements. 
301 The $T_{n}$ plots for both experimental protocols have been overlain with theoretical quartz TL

302 curves generated using the general kinetic model of quartz (Bailey, 2001) implemented in the

303 R-package 'RLumModel' (Friedrich et al., 2016, Section 3.5) by prescribing each protocol's

304 heating rate. As expected, the quartz $110^{\circ} \mathrm{C}$ peak is absent from the $L_{n}$ plots for both protocols,

305 as it is a short-lived peak with a half-life of $\sim 70 \mathrm{~min}$ (cf. Schmidt et al., 2018). We have thus

306 not plotted the theoretical quartz TL curves on the $L_{n}$ plots. The inconsistency in $110^{\circ} \mathrm{C}$ peak

307 positions between the measured and theoretical TL curves is greatly reduced in the plots of

308 Experiment Biii when compared to those of Experiment Ai. Furthermore, the Figure $2 T_{n}$ plots

309 measured using Experiment Biii have both the $110^{\circ} \mathrm{C}$ peak, associated with quartz, and a low

310 temperature peak at $\sim 140{ }^{\circ} \mathrm{C}$, commonly found in feldspars (e.g. Duller and Botter-Jensen,

311 1993), present as opposed to the $T_{n}$ plots generated using Experiment Ai where they are both

312 absent. 
Experiment Ai
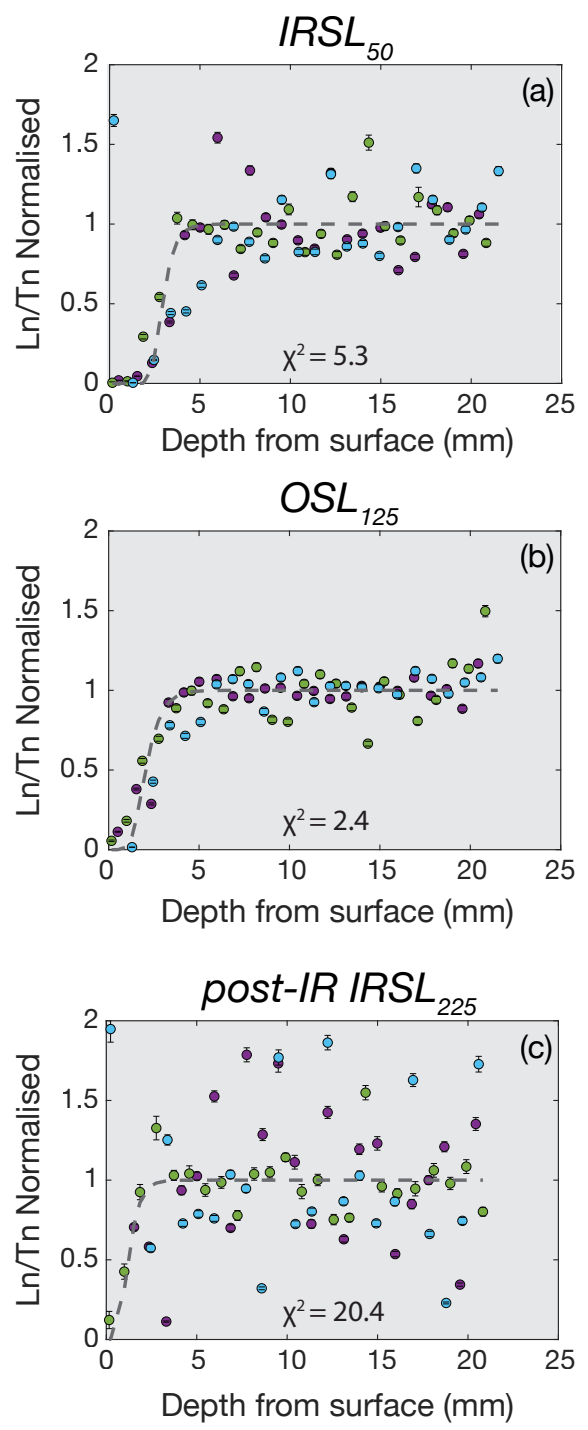

Experiment Biii
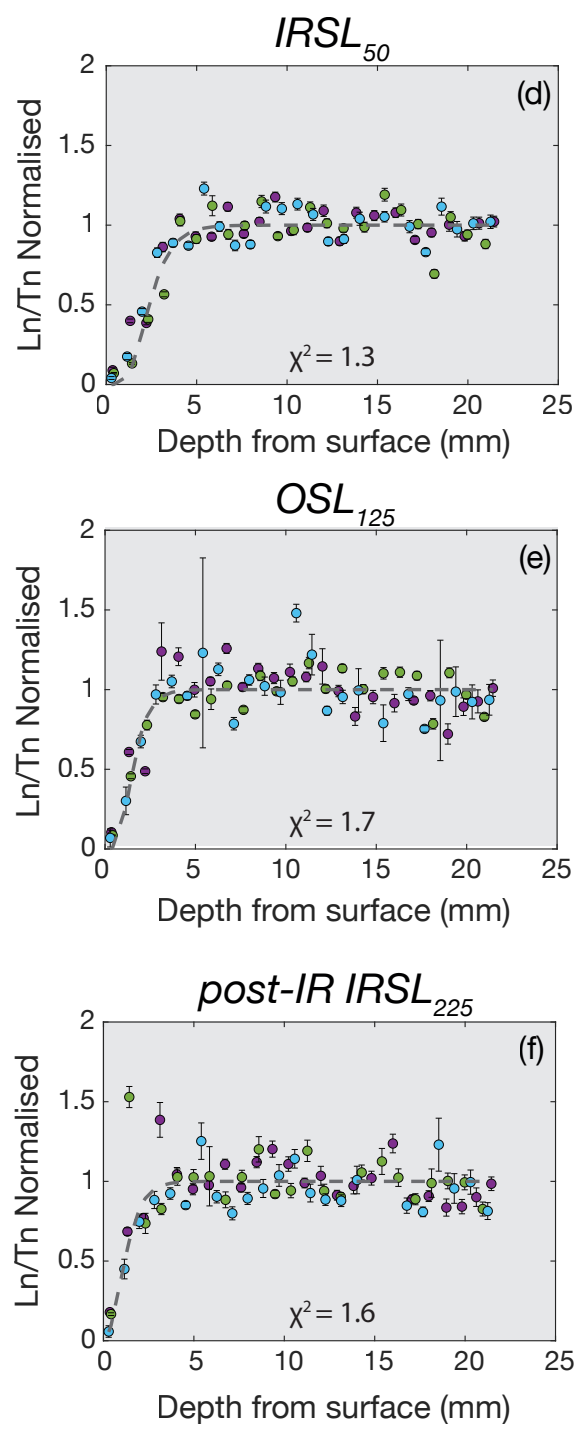

$\Phi$ Core 1 ф Core 2 \$Core 3 - - - Model

Figure 1: Luminescence depth profiles generated for the natural $\mathrm{IRSL}_{50}, \mathrm{OSL}_{125}$ and post-IR IRSL $\mathrm{IL}_{22}$ signals from sample GG18-05-01, with their corresponding modelled plots and $\chi^{2}$ values. Each profile is constructed using three separate cores (denoted by the three colours) and each point is a luminescence measurement from a slice at that particular depth. The luminescence signal is normalised in each case to the average value of the plateau, which is determined qualitatively once the luminescence signals are no longer increasing with depth. The errors are taken directly from the Analyst programme, and are derived from the square root of the luminescence counts. Experiment Ai (a-c) had $10 \mathrm{~mm}$ diameter slices resting directly on the carousel and used a heating rate of $5{ }^{\circ} \mathrm{C} \mathrm{s}^{-1}$ while Experiment Biii (d-f) had $5 \mathrm{~mm}$ diameter slices and broken fragments sat in stainless steel cups on the carousel and a heating rate of $1{ }^{\circ} \mathrm{C} \mathrm{s}^{-1}$. 


\section{Experiment Ai}
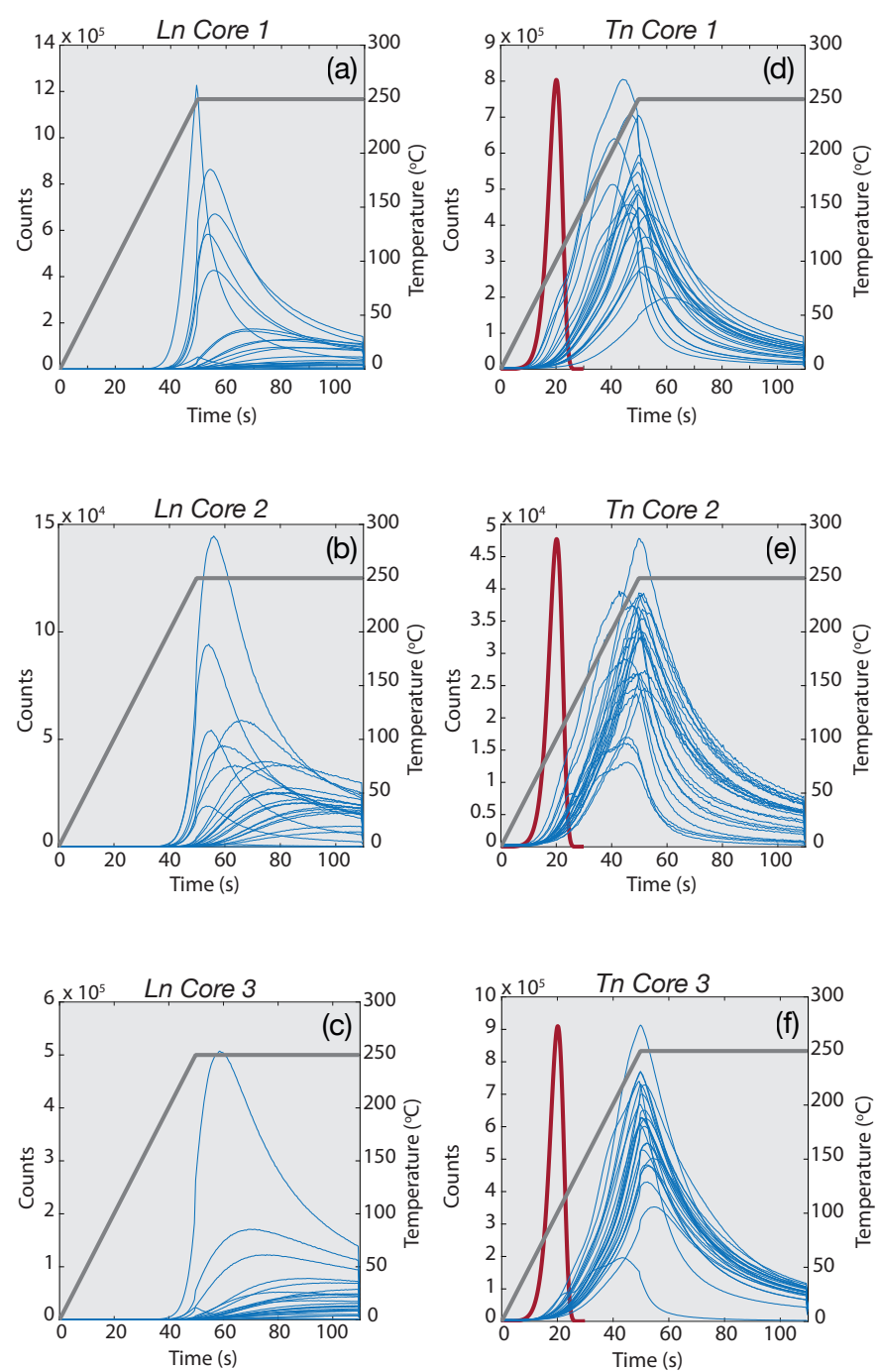

\section{Experiment Biii}
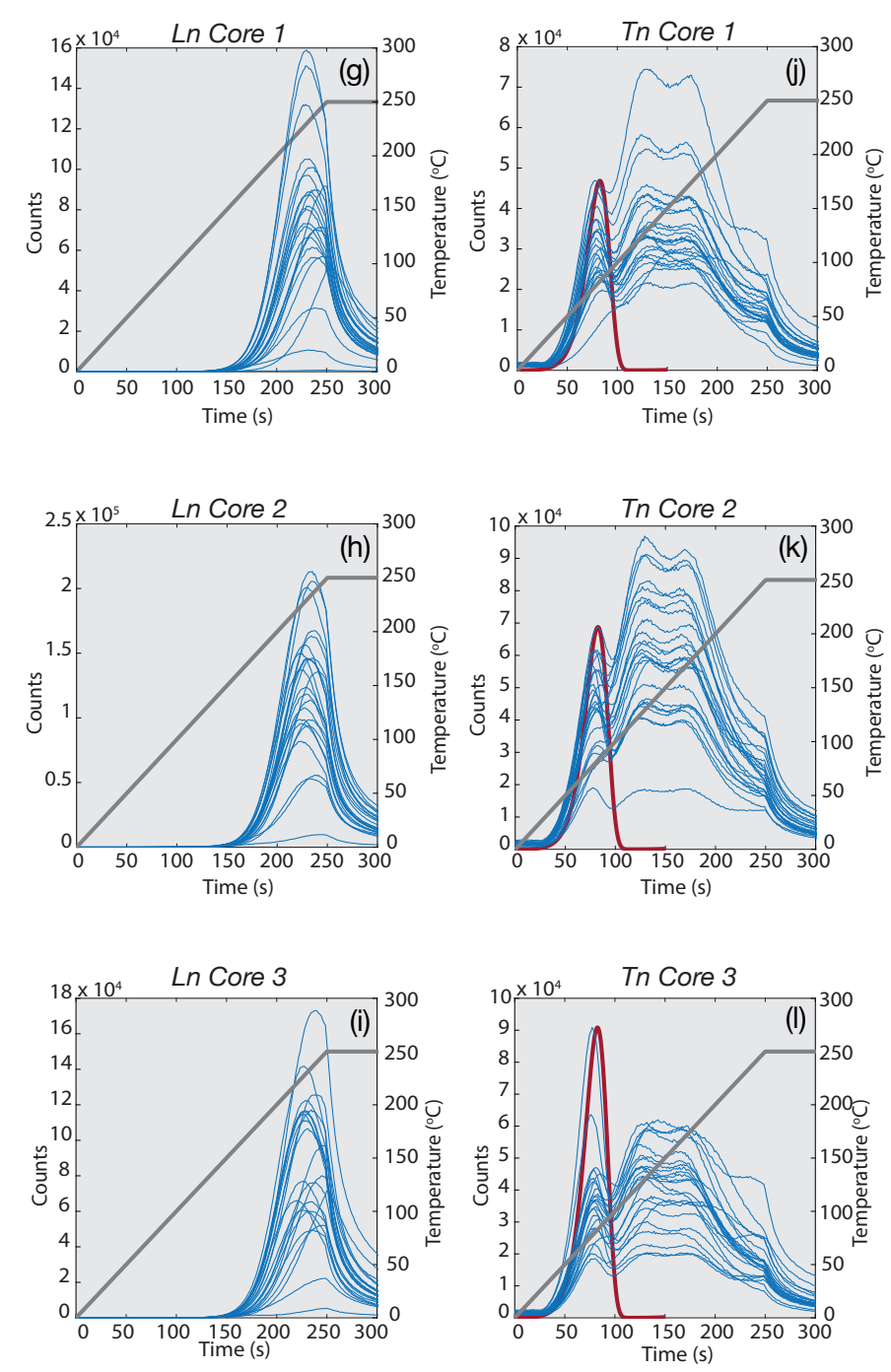

Figure 2: TL curves produced during the $L_{n}$ and $T_{n}$ measurements of the natural signal in sample GG18-05-01. Each core was up made of 24 slices. Experiment Ai (a-f) had $10 \mathrm{~mm}$ diameter slices resting directly on the carousel and Experiment Biii (g-l) had $5 \mathrm{~mm}$ diameter slices and broken fragments sat in stainless steel cups on the carousel. The theoretical quartz curves (red) were generated using the general kinetic quartz model (Bailey, 2001) implemented using the R-package 'RLumModel' (Friedrich et al., 2016) by prescribing each experimental protocol's respective heating rate. The intensity of the theoretical TL curves has been normalised to the maximum experimental peak intensity for Experiment $\mathrm{Ai}$ and their corresponding experimental $110^{\circ} \mathrm{C}$ peaks for Experiment Biii. 


\subsection{Experimental protocols}

\subsubsection{Signal properties and reproducibility}

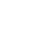

To assess reproducibility for all four experiments and three signals, each slice was measured five times following lab irradiation, and the relative standard deviation (RSD) of the $L_{x}$ signal measurements was calculated. All three signals were reproducible with RSD of $<10 \%$ for the IRSL $_{50}, \mathrm{OSL}_{125}$, and post-IR IRSL 225 signals for $94 \%$ of measurements. Furthermore, for all slices, the luminescence signals were checked for two acceptance criteria: (1) maximum error of test dose signal $\left(T_{n}\right)$ of $<15 \%$ and (2) $T_{n}$ greater than $3 \sigma$ above the background signal. Across the four experiments, all slices passed the screening for the three stimulation signals except for one $10 \mathrm{~mm}$ diameter slice which failed both tests for the post-IR IRSL 225 stimulation in Experiment Aiii and all parts of Experiment B. The slice's data from these experiments has been excluded from any further analysis.

\subsubsection{Signal intensity}

One aspect of the experiments involved comparing the use of different detection filters during IRSL measurements, particularly the effect of using a U340 filter as opposed to the blue filter pack (BG39 + BG3). To do this, the intensity of the Lx signal, for both IRSL $_{50}$ and post-IR IRSL $_{225}$, from parts (i) and (ii) of each experiment were compared. This assessment is possible because these two sections within each experiment have the same measurement conditions, in terms of the sequence order and heating parameters used. The only difference between these two parts lies in the detection filters used for the IRSL measurements- part (i) uses U340 filters whereas part (ii) the BG39+BG3 blue filter pack. Part (iii) of each experiment was excluded 


\section{This manuscript is a pre-print and has been submitted for publication in Quaternary Geochronology}

340 from analysis as it includes a change in the order of stimulation which therefore doesn't allow

341 for a clear comparison. Examples of the comparison results from Experiments B and D can be

342 found in Tables S5 and S6. For both the IRSL 50 and post-IR IRSL 225 signals, across both slice

343 sizes, the average Lx intensities from part (i) were either of equal magnitude or one magnitude

344 lower than the results from part (ii).

346 Another objective of this study entailed investigating the order of light stimulation modes,

347 specifically that of the OSL $_{125}$ and post-IR IRSL 225 signals. Parts (i) and (ii) of each experiment

348 have the $\mathrm{OSL}_{125}$ stimulation occurring prior to that of the post-IR IRSL 225 whereas in part (iii),

349 the order of these two stimulations was reversed. To understand the effect of this, the intensity

350 of the luminescence signal for each stimulation was compared across the experiments. Figure

3 shows an example of the results, taken from Experiment B. Since there was high reproducibility across the cycles (Section 4.2.1), for the remainder of this section, all signal intensity values are quoted as an average of all five cycles. In the $10 \mathrm{~mm}$ core results, the $\mathrm{OSL}_{125}$ and post-IR IRSL 225 signals, using a sequence order whereby the $\mathrm{OSL}_{125}$ stimulation occurs prior to the post-IR IRSL 225 (Experiment Bii), have signal intensity values of $12.5 \times 10^{4}$ and $3.4 \times 10^{4}$ counts/second (cts s${ }^{-1}$ ), respectively. Once the order is reversed in Experiment Biii, there is a $73.9 \%$ increase in the post-IR IRSL 225 signal intensity to $5.9 \times 10^{4} \mathrm{cts} \mathrm{s}^{-1}$ at the expense of the $\mathrm{OSL}_{125}$ signal which is reduced by $17.6 \%$ to $10.3 \times 10^{4} \mathrm{cts} \mathrm{s}^{-1}$. A similar pattern is observed for the $5 \mathrm{~mm}$ cores once the sequence order is reversed, but with a smaller

360 magnitude of change. The post-IR IRSL 225 signal increases by $50.0 \%$ from $1.0 \times 10^{4}$ to $1.5 \mathrm{x}$

$36110^{4} \mathrm{cts} \mathrm{s}^{-1}$, alongside a $19.0 \%$ decrease in $\mathrm{OSL}_{125}$ signal intensity from $4.2 \times 10^{4}$ to $3.4 \times 10^{4}$ 362 $\operatorname{cts~s}^{-1}$. 
This manuscript is a pre-print and has been submitted for publication in Quaternary Geochronology

\begin{tabular}{|c|c|c|c|c|c|}
\hline Stimulation & Filter & $\begin{array}{l}\text { Heating rate } \\
\left({ }^{\circ} \mathrm{C} \mathrm{s}^{-1}\right)\end{array}$ & $\begin{array}{l}\text { Isothermal } \\
\text { hold (s) }\end{array}$ & Signal & Target mineral \\
\hline \multicolumn{6}{|l|}{$\begin{array}{c}\text { Regenerative dose } \\
51.75 \mathrm{~Gy}\end{array}$} \\
\hline Preheat at $250^{\circ} \mathrm{C}$ & $\begin{array}{c}\mathrm{U} 340^{\mathrm{i}} / \\
\mathrm{BG} 39+\mathrm{BG} 3^{\mathrm{ii}, \mathrm{iii}}\end{array}$ & $5^{\mathrm{A}, \mathrm{D} / 1^{\mathrm{B}, \mathrm{C}}}$ & $60^{\mathbf{A}, \mathbf{C}} / 100^{\mathbf{B}, \mathbf{D}}$ & & \\
\hline IRSL at $50^{\circ} \mathrm{C}$ & $\begin{array}{c}\mathrm{U} 340^{\mathrm{i}} / \\
\mathrm{BG} 39+\mathrm{BG} 3^{\mathrm{ii}, \mathrm{iii}}\end{array}$ & $5^{\mathbf{A}, \mathbf{D}} / 1^{\mathbf{B}, \mathbf{C}}$ & $5^{\mathbf{A}, \mathbf{C}} / 100^{\mathbf{B}, \mathbf{D}}$ & $\operatorname{IRSL}_{50} L_{x}$ & Feldspar \\
\hline $\begin{array}{l}\text { OSL at } 125^{\circ} \mathrm{C}^{\mathrm{i}, \mathrm{ii} /} \\
\text { IRSL at } 225^{\circ} \mathrm{C}^{\mathrm{iii}}\end{array}$ & $\begin{array}{c}\mathrm{U} 340^{\mathrm{i}, \mathrm{ii}} / \\
\mathrm{BG} 39+\mathrm{BG} 3^{\mathrm{iii}}\end{array}$ & $5^{\mathrm{A}, \mathrm{D}} / 1^{\mathrm{B}, \mathrm{C}}$ & $5^{\mathbf{A , C}} / 100^{\mathbf{B}, \mathbf{D}}$ & $\mathrm{OSL}_{125} L_{x}$ & $\begin{array}{l}\text { Quartz }^{\mathrm{i}, \mathrm{ii}} / \\
\text { Feldspar }^{\text {iii }}\end{array}$ \\
\hline $\begin{array}{l}\text { IRSL at } 225^{\circ} \mathrm{C}^{\mathrm{i}, \mathrm{ii} /} / \\
\mathrm{OSL} \text { at } 125^{\circ} \mathrm{C}^{\mathrm{iii}}\end{array}$ & $\begin{array}{c}\mathrm{U} 340^{\mathrm{i}, \mathrm{iii} /} \\
\mathrm{BG} 39+\mathrm{BG} 3^{\mathrm{ii}}\end{array}$ & $5^{\mathrm{A}, \mathrm{D}} / 1^{\mathrm{B}, \mathrm{C}}$ & $5^{\mathrm{A}, \mathrm{C}} / 100^{\mathbf{B}, \mathbf{D}}$ & $\begin{array}{c}\text { post-IR IRSL } \\
L_{x}\end{array}$ & $\begin{array}{l}\text { Feldspar,i,i/ } \\
\text { Quartz }^{\text {iii }}\end{array}$ \\
\hline \multicolumn{6}{|l|}{$\begin{array}{l}\text { Test dose } \\
51.75 \mathrm{~Gy}\end{array}$} \\
\hline Preheat at $250^{\circ} \mathrm{C}$ & $\begin{array}{c}\mathrm{U} 340^{\mathrm{i}} / \\
\mathrm{BG} 39+\mathrm{BG} 3^{\mathrm{ii}, \mathrm{iii}}\end{array}$ & $5^{\mathrm{A}, \mathrm{D}} / 1^{\mathrm{B}, \mathrm{C}}$ & $60^{\mathbf{A}, \mathbf{C}} / 100^{\mathbf{B}, \mathbf{D}}$ & & \\
\hline IRSL at $50^{\circ} \mathrm{C}$ & $\begin{array}{c}\mathrm{U} 340^{\mathrm{i}} / \\
\mathrm{BG} 39+\mathrm{BG} 3^{\mathrm{i}, \mathrm{iii}}\end{array}$ & $5^{\mathbf{A}, \mathbf{D}} / 1^{\mathbf{B}, \mathbf{C}}$ & $5^{\mathbf{A}, \mathbf{C}} / 100^{\mathbf{B , D}}$ & $\mathrm{IRSL}_{50} T_{x}$ & Feldspar \\
\hline $\begin{array}{l}\text { OSL at } 125^{\circ} \mathrm{C}^{\mathrm{i}, \mathrm{ii} /} \\
\text { IRSL at } 225^{\circ} \mathrm{C}^{\mathrm{iii}}\end{array}$ & $\begin{array}{c}\mathrm{U} 340^{\mathrm{i}, \mathrm{ii} /} \\
\mathrm{BG} 39+\mathrm{BG} 3^{\mathrm{iii}}\end{array}$ & $5^{\mathbf{A}, \mathbf{D}} / 1^{\mathbf{B}, \mathbf{C}}$ & $5^{\mathrm{A}, \mathrm{C}} / 100^{\mathbf{B}, \mathbf{D}}$ & $\mathrm{OSL}_{125} T_{x}$ & $\begin{array}{l}\text { Quartz }^{\mathrm{i}, \mathrm{ii} /} \\
\text { Feldspar }^{\text {iii }}\end{array}$ \\
\hline $\begin{array}{l}\text { IRSL at } 225^{\circ} \mathrm{C}^{\mathrm{i}, \mathrm{ii}} / \\
\text { OSL at } 125^{\circ} \mathrm{C}^{\mathrm{iii}}\end{array}$ & $\begin{array}{c}\mathrm{U} 340^{\mathrm{i}, \mathrm{iii} /} \\
\mathrm{BG} 39+\mathrm{BG} 3^{\mathrm{ii}}\end{array}$ & $5^{\mathrm{A}, \mathrm{D}} / 1^{\mathrm{B}, \mathrm{C}}$ & $5^{\mathbf{A , C}} / 100^{\mathbf{B , D}}$ & $\begin{array}{c}\text { post-IR IRSL } \mathrm{IR}_{225} \\
T_{x}\end{array}$ & $\begin{array}{l}\text { Feldspar,i,iij } \\
\text { Quartz }\end{array}$ \\
\hline \multicolumn{6}{|c|}{ Repeat 5 times } \\
\hline
\end{tabular}

Table 2: Overview of experimental protocols tested in this study. A, B, C and D denote the different experiments and ${ }^{\mathrm{i} \text {, ii, iii }}$ represents the different parts within each experiment (i.e. there was Experiment Ai, Aii, Aiii and the same for Experiments B, C and D). A 7.5 mm U340 filter was used. 

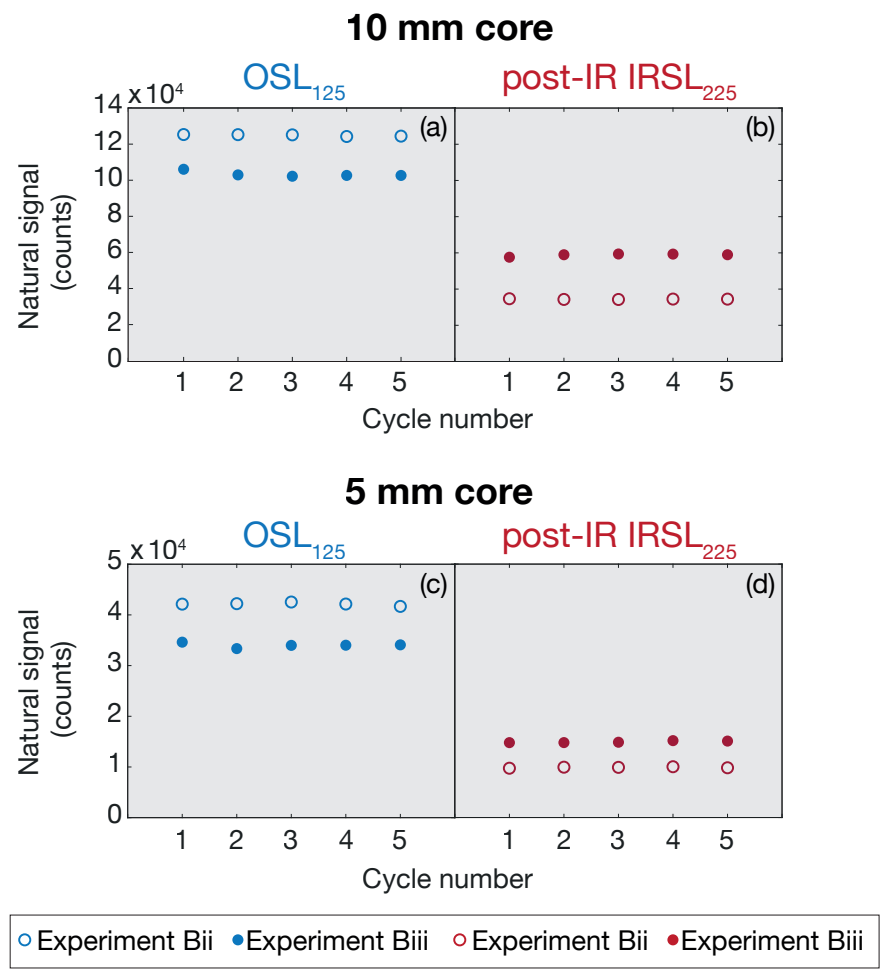

Figure 3: Comparison of $\mathrm{OSL}_{125}$ (blue) and post-IR IRSL 225 (red) natural signal counts from Experiments Bii and Biii to investigate the influence of varying the order of light stimulation. The slices were heated at a rate of $1{ }^{\circ} \mathrm{C} \mathrm{s}^{-1}$, and each protocol was run five times on each individual slice (termed cycles in the figure). (a-b) are measured from slices sat directly on the carousel and (c-d) are results for slices resting within stainless steel cups on the carousel. Open circles represent Experiment Bii, which has the $\mathrm{OSL}_{125}$ stimulation prior to the post-IR IRSL 225 stimulation. Closed circles, for Experiment Biii, has these stimulations reversed with the post-IR IRSL 225 stimulation occurring before that of the $\mathrm{OSL}_{125}$.

\subsubsection{TL curves}

381 By recording the TL signal emitted during the preheat in a sequence, we are able to glean some

382 information on the thermal treatment received by the sample. As shown in Table 2, prior to

383 stimulation each slice was subjected to a $250{ }^{\circ} \mathrm{C}$ preheat. Across the four experiments, the

384 heating rate and isothermal hold of the preheat were varied and examples of the resulting TL curves from part (iii) of each experiment are illustrated in Figure 4. 


\section{This manuscript is a pre-print and has been submitted for publication in Quaternary Geochronology}

387 For all four experiments, a consistent pattern emerges in both the TL curve peak positions and

388 shapes when comparing the results from $10 \mathrm{~mm}$ diameter slices with those of $5 \mathrm{~mm}$ diameter

389 slices. Within each experiment specifically, under the same measurement conditions, the TL

390 of the $5 \mathrm{~mm}$ diameter slices peaks earlier than the $10 \mathrm{~mm}$ diameter slices. The TL curves of 5

$391 \mathrm{~mm}$ diameter slices also have more of their TL curves emerging prior to the heating plate

392 attaining its maximum temperature, when compared to their $10 \mathrm{~mm}$ slices diameter counterparts. In addition, the shape of the TL curves for the $5 \mathrm{~mm}$ diameter slices is different

394 with more pronounced peaks and troughs than that of the $10 \mathrm{~mm}$ diameter slices. This

395 difference in shape is not solely observed within specific experiments, but also across

396 experiments. For example, there is a distinct difference in shape when looking at the $10 \mathrm{~mm}$

397 diameter slice TL curves in Experiments Aiii (Fig. 4a) and Diii (Fig. 4d) as opposed to a 10

398 mm diameter slice result in Experiment Biii (Fig. 4b) or Experiment Ciii (Fig. 4c). The slices

399 heated using a lower heating rate of $1{ }^{\circ} \mathrm{C} \mathrm{s}^{-1}$ (Fig. $4 \mathrm{~b}$ and $4 \mathrm{c}$, Experiments Biii and Ciii) have a

400 more pronounced expression of the low temperature peak when compared to the slices

401 subjected to a higher heating rate of $5{ }^{\circ} \mathrm{C} \mathrm{s}^{-1}$ (Fig. 4a and 4d, Experiments Aiii and Diii) where

402 this low temperature peak is either missing or merged with the higher temperature peak. The

$40310 \mathrm{~mm}$ diameter slices, heated at $1{ }^{\circ} \mathrm{C} \mathrm{s}^{-1}$ rate, also had their peaks slightly shifted away from

404 the maximum temperature, but not to the extent of the $5 \mathrm{~mm}$ diameter slices. 

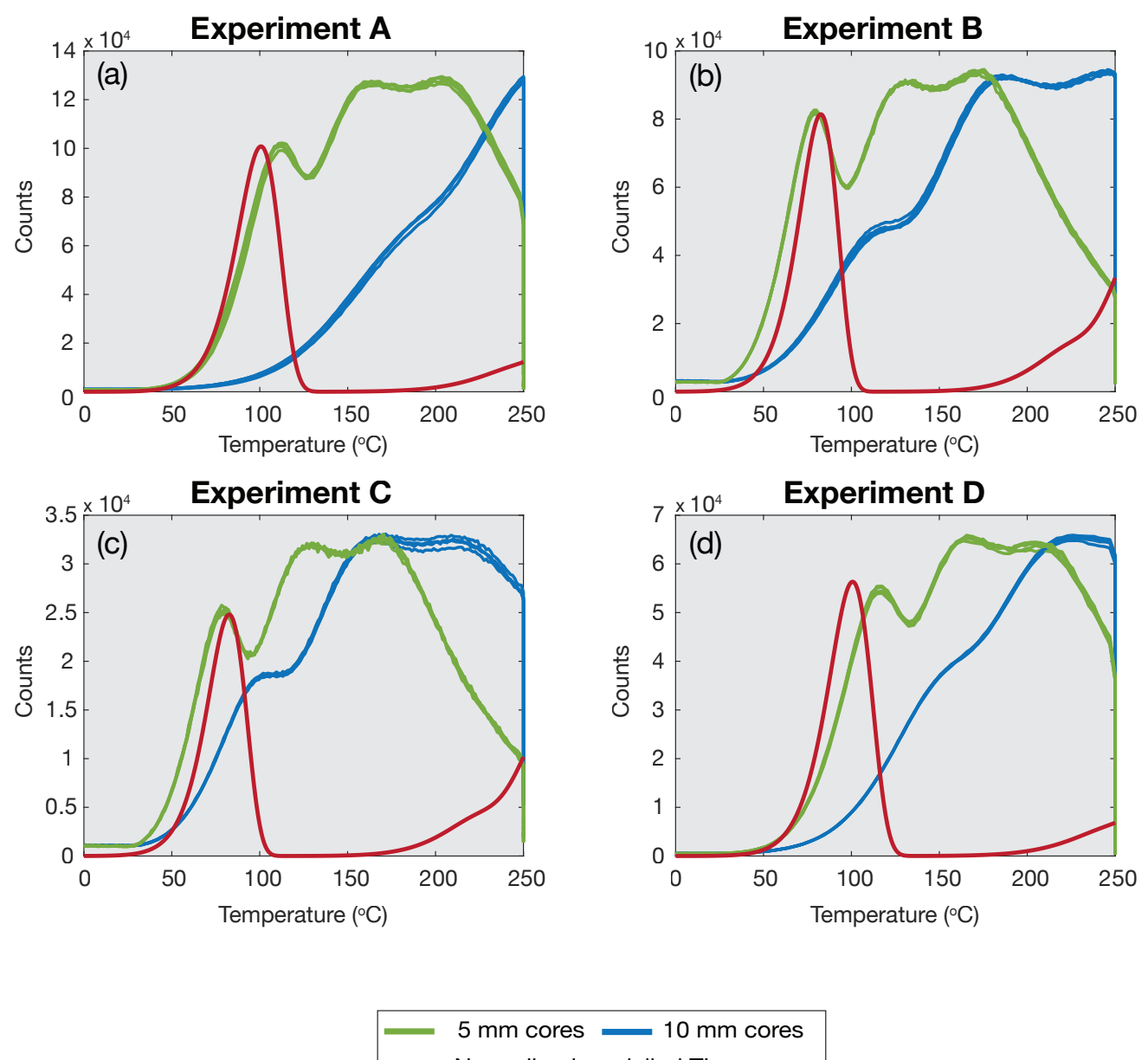

Normalised modelled TL curve

Figure 4: Theoretical quartz TL curves superimposed onto experimental TL curves from part (iii) of each experiment in this study. The theoretical quartz curves (red) were generated using the general kinetic quartz model (Bailey, 2001) implemented using the R-package 'RLumModel' (Friedrich et al., 2016) by prescribing each experiment's respective heating rate. The $10 \mathrm{~mm}$ diameter slices (blue) were resting directly on the carousel while the $5 \mathrm{~mm}$ diameter slices (green) sat in stainless steel cups on the carousel. The slices were heated to $250{ }^{\circ} \mathrm{C}$, for Experiments $\mathrm{A}$ and $\mathrm{D}$ the heating rate was $5{ }^{\circ} \mathrm{C} \mathrm{s}^{-1}$ whereas $\mathrm{B}$ and $\mathrm{C}$ were heated at a rate of $1{ }^{\circ} \mathrm{C} \mathrm{s}^{-1}$, and each slice was measured five times. The intensity of the theoretical TL curves has been normalised to their corresponding experimental $5 \mathrm{~mm}$ diameter $110^{\circ} \mathrm{C}$ peaks. The intensity of the $10 \mathrm{~mm}$ diameter TL curves has also been normalised to their corresponding $5 \mathrm{~mm}$ diameter TL curves. 


\section{This manuscript is a pre-print and has been submitted for publication in Quaternary}

Geochronology

408

409

410

411

412

413

414

415

416

417

418

419

420

421

422

423

424

425

426

427

428

429

430

431

432

\subsubsection{Kinetic modelling}

Modelled quartz TL curves are used to show the theoretical $110^{\circ} \mathrm{C}$ peak position in the absence of any thermal lag, for a specific heating rate. By comparing these theoretical TL curves to experimentally generated TL curves, we are able to quantitavely evaluate the degree of thermal lag experienced by a sample. In this case however, as we are working with a signal resultant from an amalgamation of minerals and not pure quartz, isolating the exact positions of the 110 ${ }^{\circ} \mathrm{C}$ peak from the $10 \mathrm{~mm}$ diameter slice TL curves that our experiments had produced is difficult, as the overall TL curve is likely composed of several smaller sub-peaks. Therefore, the experimental $110^{\circ} \mathrm{C}$ peak positions were visually estimated. Theoretical quartz TL curves were generated using the general kinetic model of quartz (Bailey, 2001) implemented in the Rpackage 'RLumModel' (Friedrich et al., 2016; Section 3.5) by prescribing each experiment's respective heating rate. Superimposing the modelled curves on the experimental TL curves (Fig. 4) reveals a pronounced mismatch in the theoretical and experimental positions of the 110 ${ }^{\circ} \mathrm{C}$ peak in results from Experiments $\mathrm{A}$ and $\mathrm{D}\left(5^{\circ} \mathrm{C} \mathrm{s}^{-1}\right.$ heating rate $)$ as opposed to the results from Experiments $\mathrm{B}$ and $\mathrm{C}\left(1{ }^{\circ} \mathrm{C} \mathrm{s}^{-1}\right.$ heating rate). The discrepancy in theoretical and experimental peak positions is reduced further when comparing the $5 \mathrm{~mm}$ diameter slice TL curves to their $10 \mathrm{~mm}$ diameter slice counterparts within each individual experiment - even for the $10 \mathrm{~mm}$ diameter slice experiments with low heating rates. This is emphasised in Table 4, which states the maximum peak position values for the $110^{\circ} \mathrm{C}$ theoretical and experimental peaks in each experiment. Across the five cycles for both the $10 \mathrm{~mm}$ and $5 \mathrm{~mm}$ diameter slices in all four experiments, the peak positions were reproducible with a $\mathrm{RSD}<1.5 \%$. 
This manuscript is a pre-print and has been submitted for publication in Quaternary Geochronology

\begin{tabular}{cc|c|c|c}
\hline & & \multicolumn{3}{|c}{$110^{\circ} \mathrm{C}$ peak positions } \\
\hline & & $\begin{array}{c}10 \mathrm{~mm} \text { diameter } \\
\text { slice }\end{array}$ & $\begin{array}{c}5 \mathrm{~mm} \text { diameter } \\
\text { slice }\end{array}$ & \multirow{2}{*}{ Theoretical } \\
\cline { 1 - 3 } & Experimental & Experimental & \\
\cline { 1 - 3 } Experiment & $\begin{array}{c}\text { Heating rate } \\
\left({ }^{\circ} \mathrm{C} \mathrm{s}^{-1}\right)\end{array}$ & Temperature $\left({ }^{\circ} \mathrm{C}\right)$ & Temperature $\left({ }^{\circ} \mathrm{C}\right)$ & Temperature $\left({ }^{\circ} \mathrm{C}\right)$ \\
\hline A & 5 & $\sim 185.8$ & 112.8 & 100.5 \\
\hline B & 1 & $\sim 115.2$ & 78.6 & 82.6 \\
\hline C & 1 & 100.8 & 78.4 & 82.6 \\
\hline D & 5 & $\sim 159.6$ & 117.5 & 100.5 \\
\hline
\end{tabular}

Table 4: Comparison of experimental and theoretical $110^{\circ} \mathrm{C}$ peak positions across all four kinetic model of quartz (Bailey, 2001) implemented in the R-package 'RLumModel' (Friedrich et al., 2016) by prescribing the heating rates for each experiment. For the Experimental $10 \mathrm{~mm}$ slice there is not a clear peak present but instead a shoulder (Fig. 4).

Additionally, we attempted to calculate kinetic parameters for the trap giving rise to the 110

${ }^{\circ} \mathrm{C}$ peak for these samples, following the isothermal decay method outlined in Schmidt et al. (2018), but were unfortunately unable to generate realistic values due to feldspar contamination.

\subsubsection{Luminescence decay curves}

447 Figure 5 shows examples of post-IR IRSL $_{22}$ decay curves for $10 \mathrm{~mm}$ and $5 \mathrm{~mm}$ diameter slices across all four experiments. There is a clear difference between results from the two diameters.

449 For all four experiments, the $10 \mathrm{~mm}$ diameter slice luminescence curves continue to rise even once the diodes have been switched on, and only peak after $\sim 40 \mathrm{~s}$ of stimulation. In contrast, the $5 \mathrm{~mm}$ diameter slice decay curves have the characteristic luminescence decay shape 


\section{This manuscript is a pre-print and has been submitted for publication in Quaternary Geochronology}

455
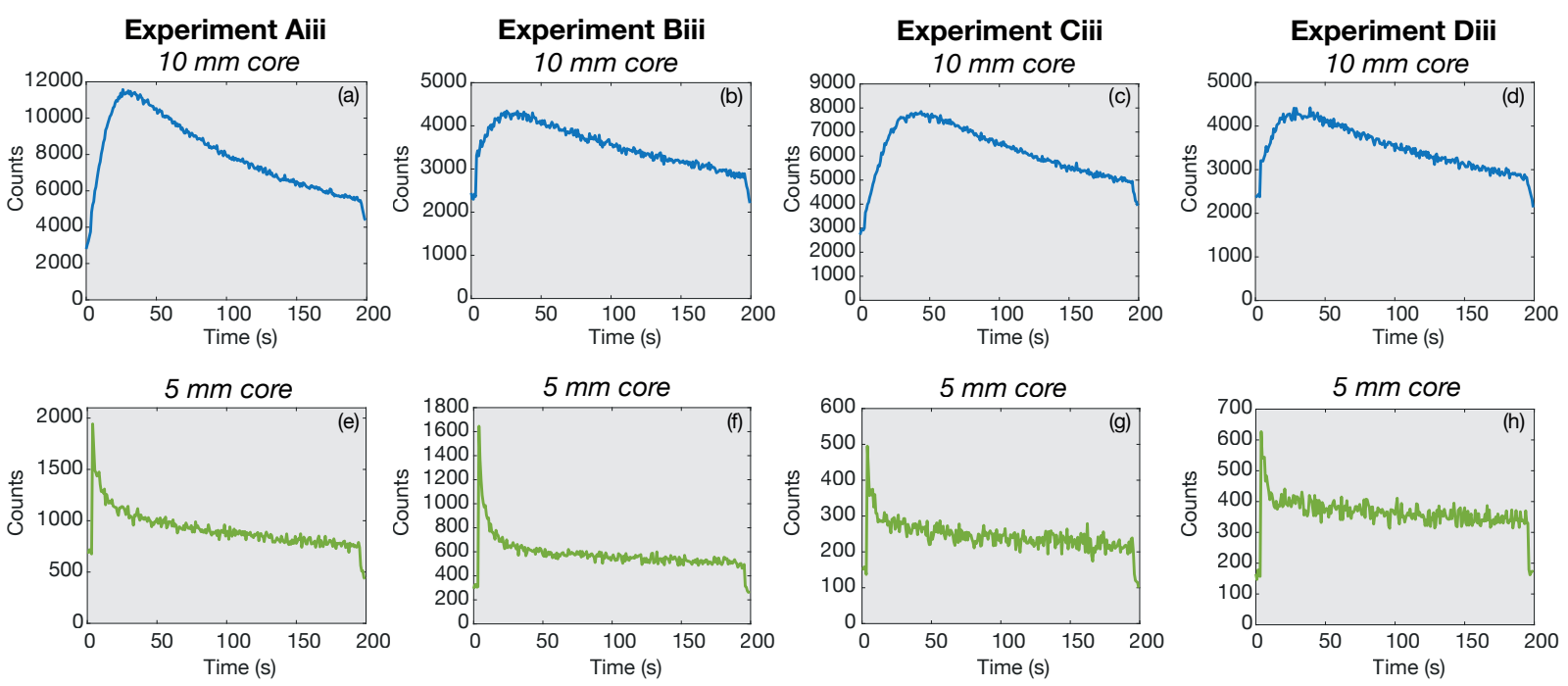

Figure 5: Post-IR IRSL 225 luminescence decay curves for $10 \mathrm{~mm}$ diameter slices (a-d) and $5 \mathrm{~mm}$ diameter slices

(e-h) across all four experiments. The $10 \mathrm{~mm}$ diameter slices were resting directly on the carousel during measurement while the $5 \mathrm{~mm}$ diameter slices were in stainless steel cups. All four were subjected to protocols which had the post-IR IRSL 225 stimulation occurring after the $\mathrm{IRSL}_{50}$ but prior to the $\mathrm{OSL}_{125}$ stimulations.

\subsubsection{Slice diameter}

We decided to investigate the importance of slice diameter on the luminescence profiles generated. To do this, luminescence profiles with depth for Sample GG17-05-01 were produced using two different core diameters, but with all slices resting in stainless steel cups during measurement. One profile was from $5 \mathrm{~mm}$ diameter slices, and the other from what were initially $10 \mathrm{~mm}$ diameter slices but had been broken into smaller fragments to fit inside

463 the stainless steel cups. The fragments had approximate surface areas of $25 \mathrm{~mm}^{2}$. The results are shown in Figure 6 and we see that the two luminescence profiles generated are very similar, 


\section{This manuscript is a pre-print and has been submitted for publication in Quaternary Geochronology}

implying that for this lithology slice diameter is inconsequential to the results, and that the predominant factor is the placement of all rock slices in stainless steel cups.
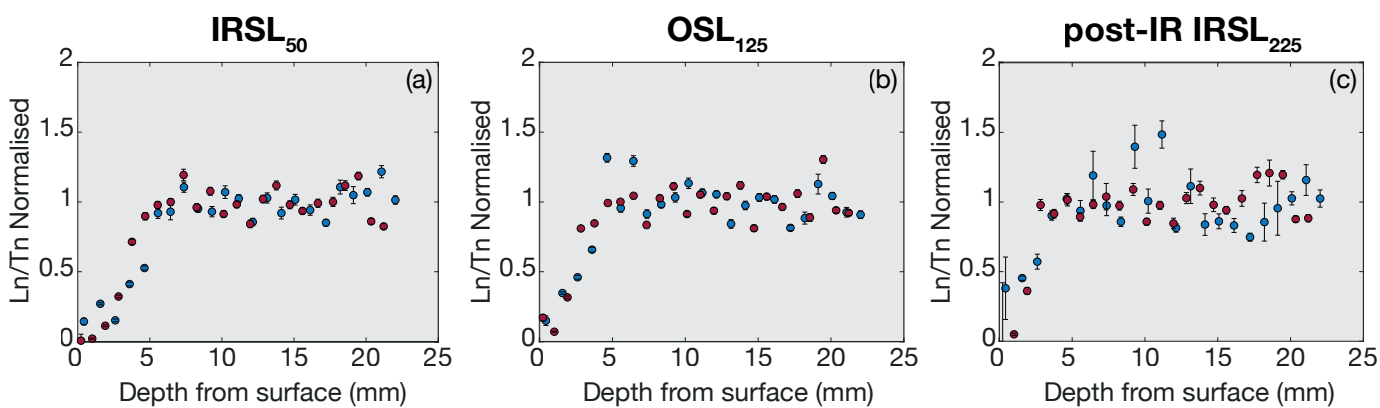

$\Phi 5 \mathrm{~mm}$ core $\$$ Broken fragments

Figure 6: Comparison between the luminescence profiles for the (a) $\operatorname{IRSL}_{50}$, (b) $\mathrm{OSL}_{125}$ and (c) post-IR $\mathrm{IRSL}_{225}$ signals generated from broken fragments (red) and $5 \mathrm{~mm}$ diameter slices (blue). Both were placed in stainless steel cups during measurement. The slices were prepared from cores of Sample GG17-05-01, and the measurement protocol applied was that of Experiment Biii. The errors are derived from the square root of the luminescence counts.

\section{Discussion}

\subsection{Filter choice and order of stimulation}

472 Following the comparison of detection filters in Section 4.2.2, a sequence which uses the BG39

$473+$ BG3 blue filter pack for IRSL measurements was deemed more suitable as it potentially 474 allows brighter signals to be measured, and the transmission of this filter pack is better centred on the feldspar emission of $410 \mathrm{~nm}$. The reduction in $\mathrm{IRSL}_{50}$ absolute signal counts for the natural samples when comparing the results of applying measurement protocol $\mathrm{Ai}$ as opposed

477 to protocol Biii is attributed to a difference in surface area of the stimulated samples- protocol 478 Ai used slices of $10 \mathrm{~mm}$ diameter whereas protocol Biii had a combination of both $5 \mathrm{~mm}$ diameter slices and broken fragments. Regarding the order of stimulation, Figure 3 


\section{This manuscript is a pre-print and has been submitted for publication in Quaternary Geochronology}

480 demonstrates that, for both slice diameters, a measurement protocol where the post-IR IRSL 225

481 stimulation occurs prior to that of $\mathrm{OSL}_{125}$ results in an improvement in the post-IR IRSL 225

482 signal intensity without greatly reducing the $\mathrm{OSL}_{125}$ signal. This is because the results show

483 that a stimulation at $225^{\circ} \mathrm{C}$ for $200 \mathrm{~s}$ has the ability to deplete an OSL signal, when present.

484 Therefore, for measurement on these samples, a sequence order which has the post-IR IRSL 225

485 stimulation preceding that of $\mathrm{OSL}_{125}$ is more appropriate.

486

\subsection{Thermal lag}

488

489

The results showed substantial differences in the TL (Fig. 4) and luminescence decay curves

(Fig. 5) observed across experiments and slice diameters, as well as highly scattered luminescence results and variable TL peak positions in natural samples measured using experimental protocol Ai as opposed to those measured using protocol Biii (Fig. 2). Since the Risø reader performance was confirmed (Section 3.4), these variations may be attributable to thermal lag. This occurs when a sample is unable to heat at the same rate as the heater plate, and therefore a delay exists between the temperature of the sample compared to the heater plate. The experiments conducted suggest that the effect of thermal lag is more pronounced in results for $10 \mathrm{~mm}$ diameter slices than $5 \mathrm{~mm}$ diameter slices, and in the post-IR $\mathrm{IRSL}_{225}$ signal as opposed to the IRSL 50 and $\mathrm{OSL}_{125}$ signals. This can be explained by the fact that a better thermal contact is achieved between the heater plate and sample when slices are placed within

500 stainless steel cups. In addition, $10 \mathrm{~mm}$ slices resting directly on the carousel as opposed to stainless steel cups are more susceptible to movement during measurement which may affect thermal contact with the heater plate. The movement of slices in the first few measurement steps of a sequence, when the sample is raised by the lift for heating or stimulation, could

504 therefore account for some of the scatter in the $10 \mathrm{~mm}$ diameter slices. 


\section{This manuscript is a pre-print and has been submitted for publication in Quaternary Geochronology}

505

506 The TL curve results demonstrate that slices subjected to a lower heating rate, and with a

507 smaller diameter in stainless steel cups, heat with conditions more similar to those programmed 508 in the sequence. This is shown by a smaller discrepancy between the theoretical and 509 experimental peak positions of the $110{ }^{\circ} \mathrm{C}$ peak. The idea is also supported by the lack of peaks 510 and troughs in the TL curves of slices heated at a higher rate $\left(5^{\circ} \mathrm{C} \mathrm{s}^{-1}\right)$. The higher heating rate 511 means that the specific temperatures required to evict unstable charge are either being reached

512 with a delay, not being reached at all or are not held for the necessary amount of time prior to 513 optical stimulation.

515 Additional modelling using a general kinetic model for quartz (Bailey, 2001) in the R-package 'RLumModel' (Friedrich et al., 2016) confirmed that heating was inconsistent, particularly for the $10 \mathrm{~mm}$ slices. Since the $10 \mathrm{~mm}$ diameter slice results showed the greatest differences in the modelled and experimental $110{ }^{\circ} \mathrm{C}$ peak positions, we sought to better comprehend the thermal conditions that these slices were experiencing. To do this, theoretical quartz TL curves across a range of heating rates, from $0.5^{\circ} \mathrm{C} \mathrm{s}^{-1}$ to $5{ }^{\circ} \mathrm{C} \mathrm{s}^{-1}$, were simulated. The experimental $110{ }^{\circ} \mathrm{C}$ peak positions were determined visually. The modelled curves were then compared to the experimental TL curves to find the theoretical curve that corresponded best with the data, the results of which are shown in Figure 7. All four experiments had their $10 \mathrm{~mm}$ diameter slices effectively heated at a lower rate than prescribed - Experiments A and D were programmed to have a heating rate of $5^{\circ} \mathrm{C} \mathrm{s}^{-1}$, yet the samples' TL curves were more representative of a heating rate of $\sim 3{ }^{\circ} \mathrm{C} \mathrm{s}^{-1}$. The same pattern is observed in the slices of Experiments $\mathrm{B}$ and $\mathrm{C}$, which were assumed to have a heating rate of $1{ }^{\circ} \mathrm{C} \mathrm{s}^{-1}$ but, according to the model calculations, were

528 heated at a rate closer to $\sim 0.8^{\circ} \mathrm{C} \mathrm{s}^{-1}$. However, these heating rates deduced from the modelling cannot be taken as absolute values, as the kinetic parameters of Bailey (2001) used to model 


\section{This manuscript is a pre-print and has been submitted for publication in Quaternary Geochronology}

530 the TL curves were also obtained experimentally and thus may also include an unknown

531 amount of thermal lag. Therefore, the inference drawn about the actual heating rate experienced

532 by the samples by comparison to modelled data might still suffer from an aspect of systematic

533 uncertainty.
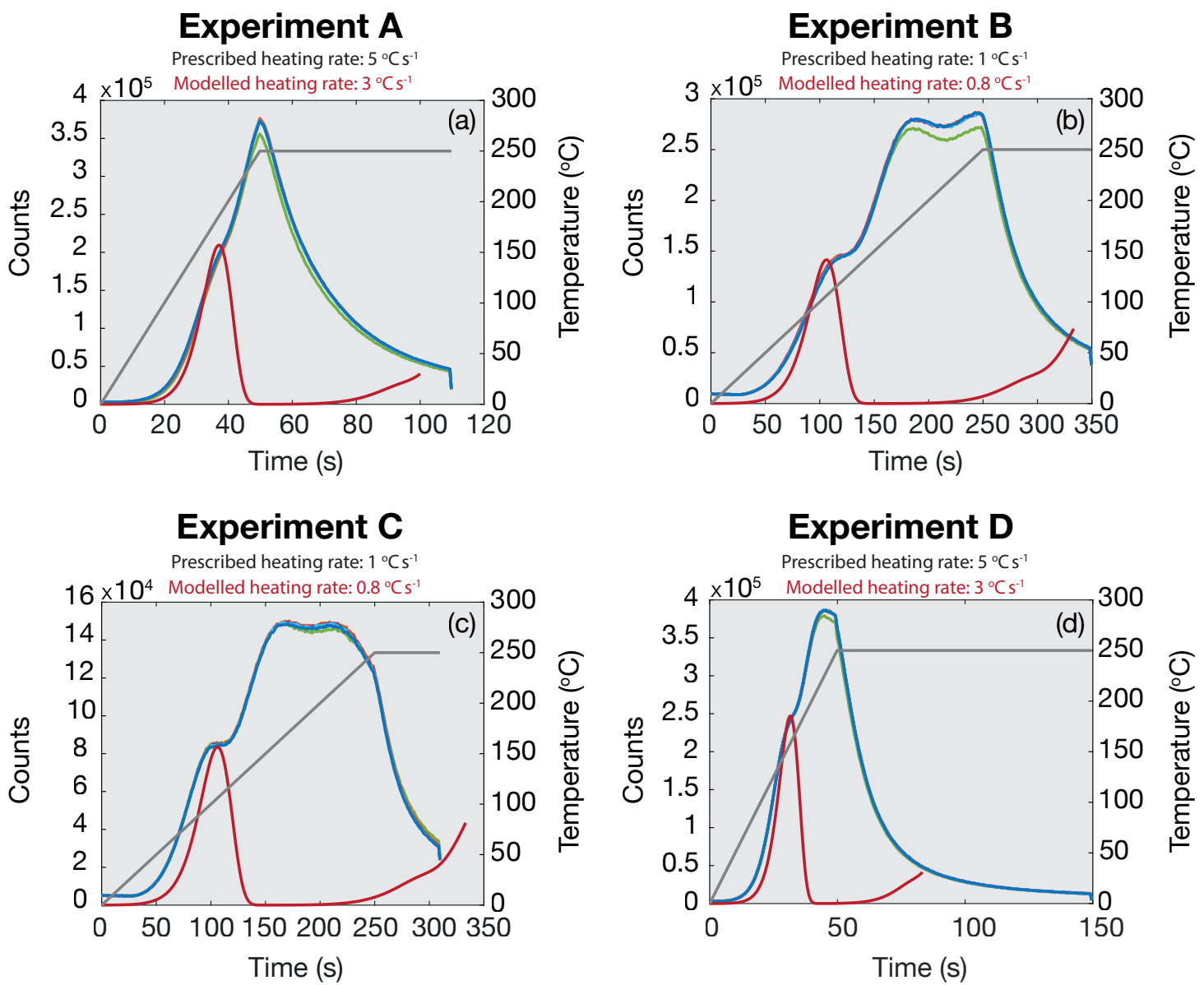

$$
\begin{gathered}
\text {-Cycle } 1 \text { - Cycle } 2-\text { Cycle } 3-\text { Cycle } 4 \text { - Cycle } 5 \\
\text {-Temperature }- \text { Normalised modelled TL curve }
\end{gathered}
$$

Figure 7: Experimental TL curves across four experiments for $10 \mathrm{~mm}$ diameter slices superimposed with the modelled quartz TL curve that best represents the data (red). Experiments A (a) and D (d) measurement results were generated using a prescribed heating rate of $5^{\circ} \mathrm{C} \mathrm{s}^{-1}$, but modelling results show that the data are better represented with a heating rate of $3{ }^{\circ} \mathrm{C} \mathrm{s}^{-1}$. Experiments B (b) and C (c) measurement results were generated using a prescribed heating rate of $1{ }^{\circ} \mathrm{C} \mathrm{s}^{-1}$, but match more closely with modelled TL curves representing a heating rate of $0.8^{\circ} \mathrm{C} \mathrm{s}^{-1}$. 


\section{This manuscript is a pre-print and has been submitted for publication in Quaternary Geochronology}

535 Evidence of thermal lag is also visible when looking at the post-IR IRSL 225 luminescence decay

536

537 curves. As mentioned in Section 4.2.5, there is a "hump" shape observed in the $10 \mathrm{~mm}$ diameter slice luminescence decay curves, irrespective of heating rate or isothermal hold duration (Fig. 5). This is indicative of thermal lag because it is assumed that, following the prescribed heating and pre-stimulation isothermal hold, the sample will have reached the desired temperature. Therefore, once the diodes are switched on, the luminescence signal should begin to decay. Instead, we observe the signal continuing to increase even once the diodes have been switched on, which suggests that the sample's temperature was still rising and had not attained a steady value as intended in the sequence programming. This raises the issue of what integration limits to set during data analysis of curves with such shapes. Jain et al. (2007) reported similar luminescence curve shapes for quartz aliquots, and also attributed the initial rise in intensity (and hence overall "hump" shape) to a delay in sample temperature compared to heater plate temperature. In contrast, the $5 \mathrm{~mm}$ diameter slices present characteristic luminescence decay shapes once the diodes are switched on, for all experimental conditions. As the two slice diameter types were subjected to identical measurement conditions in each experiment, the considerable improvement between the $10 \mathrm{~mm}$ diameter and $5 \mathrm{~mm}$ diameter slices' post-IR IRSL $_{225}$ luminescence decay curve results is attributed to improved thermal conductivity when slices are placed in stainless steel cups. The presence of metal between the heater plate and slice allows for better thermal transfer and so the sample is able to heat more rapidly and uniformly than when the slices are sat directly on the carousel.

Whereas our experimental data for both the 5 and $10 \mathrm{~mm}$ diameter cores are highly reproducible, the natural TL curves of the $10 \mathrm{~mm}$ diameter cores that have been directly placed on the heater plate highly variable between slices (Fig. 2). The cause of the observed TL variability may be due to differences in slice thickness or variable contact between the different 


\section{This manuscript is a pre-print and has been submitted for publication in Quaternary Geochronology}

$56010 \mathrm{~mm}$ diameter slices and the heater plate (Fig. 2a-f). In contrast, the $5 \mathrm{~mm}$ diameter slices

561 mounted in stainless steel cups exhibit more reproducible behaviour, reflecting uniform contact

562 and heating between measurement cycles.

563

564 Overall, the results of the TL curves and luminescence decay curves suggest that while it is

565 beneficial to decrease the heating rate of our samples to reduce the effect of thermal lag, as

566 proposed for the measurement of aliquots by Jain et al. (2007), it is also advised to keep the

567 samples in stainless steel cups when measuring rock slices.

568

569

\subsection{Exploring a physical process responsible for the scatter in luminescence signals}

570

571 Comparison of the TL curves measured for the natural signal of GG18-05-01 illustrate

considerable variability between $10 \mathrm{~mm}$ diameter slices measured using protocol Ai, relative to the $5 \mathrm{~mm}$ diameter slices measured using protocol Biii (Fig. 2), indicating that a difference in sample heating may explain the relatively noisy IRSL data obtained (Fig. 1). However, in their study of three K-feldspar samples, Murray et al. (2009) showed that the IRSL ${ }_{50}$ signal of feldspar is insensitive to preheat temperature, making the cause of our observed scatter (Fig. 1) difficult to explain. We conducted a series of further experiments and calculations to try to determine whether our feldspar samples were sensitive to different preheat temperatures and to explain our observations.

Murray et al. (2009) found that the TL trap contribution to the IRSL $_{50}$ signal of feldspar is related to a TL peak at $\sim 410{ }^{\circ} \mathrm{C}$, whilst a lower temperature peak at $\sim 140{ }^{\circ} \mathrm{C}$ was present but

583 does not contribute to the $\mathrm{IRSL}_{50}$ signal. To investigate this, thermo-optical luminescence

584 (TOL) measurements on a $10 \mathrm{~mm}$ diameter slice were undertaken- the temperature of the slice 


\section{This manuscript is a pre-print and has been submitted for publication in Quaternary Geochronology}

585 was heated up to $450{ }^{\circ} \mathrm{C}$, once at a rate of $1{ }^{\circ} \mathrm{C} \mathrm{s}^{-1}$ and then at $5{ }^{\circ} \mathrm{C} \mathrm{s}^{-1}$, while quick $(0.2 \mathrm{~s})$, 586 periodic IRSL measurements were taken every 2 seconds. This was repeated five times for

587 reproducibility purposes. The results indicated that the $140{ }^{\circ} \mathrm{C}$ TL peak does emit an IRSL 588 signal (Fig. S1), that could potentially contribute to the IRSL $_{50}$ or IRSL $_{22}$ signals where 589 preheating has not been sufficient. To explore this, we tested whether the $\operatorname{IRSL}_{50}$ and IRSL $_{225}$ signals of our samples were sensitive to different preheat temperatures by modifying the experiment conducted in Figure 3a of Murray et al. (2009). We irradiated our samples with a dose of $57.75 \mathrm{~Gy}$, and then preheated them at temperatures from $70{ }^{\circ} \mathrm{C}$ to $340{ }^{\circ} \mathrm{C}$ (in $30{ }^{\circ} \mathrm{C}$ increments). To mimic our experimental set up, this preheat was applied for either 60 or $100 \mathrm{~s}$, using both heating rates of $1{ }^{\circ} \mathrm{C} \mathrm{s}^{-1}$ and $5{ }^{\circ} \mathrm{C} \mathrm{s}^{-1}$, before measuring the IRSL 50 and post-IR $\mathrm{IRSL}_{225}$ signals. Test dose measurements were made under the same experimental conditions. In agreement with the results of Murray et al. (2009), only minor differences $(<5 \%)$ in $L_{\mathrm{x}} / T_{\mathrm{x}}$ values were recorded as a function of preheat temperature, with the largest differences occurring following the highest temperature preheats, conditions that our samples were not exposed to during the generation of Fig. 1. Finally, using literature values we calculated the potential thermal depletion of the IRSL $_{50}$ and post-IR IRSL 225 signals for a $250{ }^{\circ} \mathrm{C}$ preheat for $60 \mathrm{~s}$, which is the most stringent possible preheat for samples in this study, and found that no significant signal depletion is anticipated (Fig. 8b). Further calculations were done to try and better understand the effect of inter-slice heating variability, assuming that thermal lag hinders samples from attaining the prescribed preheat temperature $\left(250{ }^{\circ} \mathrm{C}\right.$ in this case), but that the

605 degree of thermal lag varies between slices, subsequently affecting the amount of trapped charge released. A value of $46{ }^{\circ} \mathrm{C}$ was chosen as an estimate of the maximum thermal lag,

607 taken from the greatest difference in Tn peak position in Figure 2. The trapped charge 608 remaining after holding K-feldspar for $60 \mathrm{~s}$ across 100 iterations of randomly generated preheat 609 temperature values from $204-250{ }^{\circ} \mathrm{C}$ is plotted in Figure $8 \mathrm{c}-\mathrm{d}$. For the $\mathrm{IRSL}_{50}$ signal, the 
610 temperature variation induces up to $3.3 \%$ scatter and up to $0.1 \%$ for the post-IR IRSL 225 signal

611 (calculations made using the band tail states model ( $\mathrm{Li}$ and $\mathrm{Li}, 2013$ ) and kinetic parameters of

612 sample UNIL/NB123 from King et al., 2016). These values are less than the scatter observed
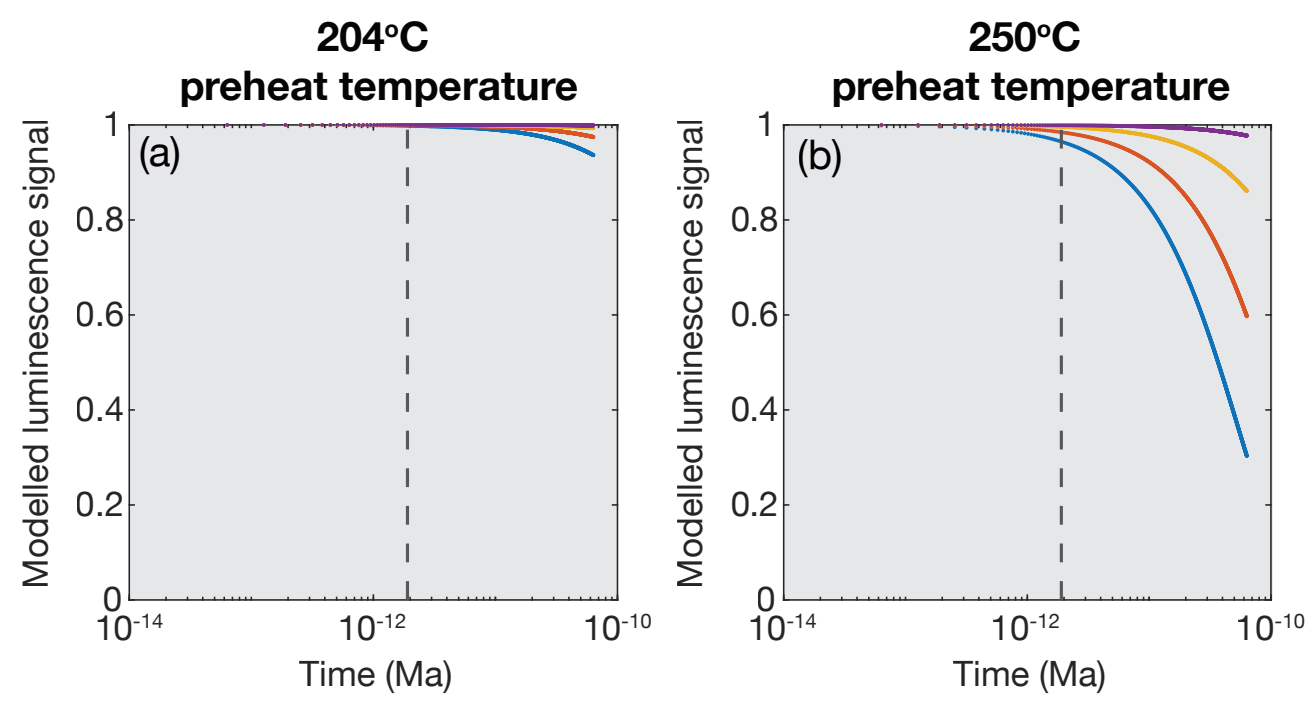

$$
\begin{gathered}
\hline \mathrm{IRSL}_{50} \cdot \mathrm{IRSL}_{100} \cdot \mathrm{IRSL}_{150} \cdot \mathrm{IRSL}_{225} \\
--60 \text { seconds }
\end{gathered}
$$
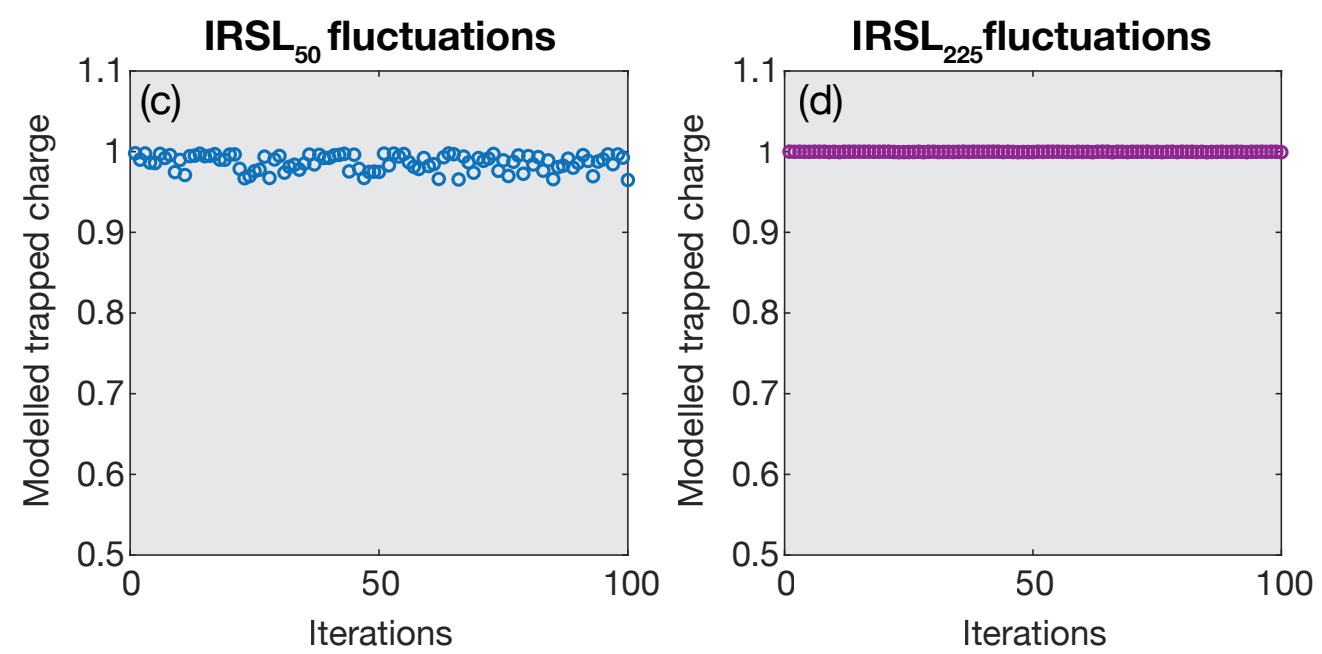

Figure 8: Stimulated isothermal decay at $204{ }^{\circ} \mathrm{C}$ (a) and $250{ }^{\circ} \mathrm{C}$ (b) for $2000 \mathrm{~s}$ using the band tail states model (Li and Li, 2013) and kinetic parameters for sample UNIL/NB123 from King et al., 2015. Depletion after $60 \mathrm{~s}$ of holding is marked on the figure. The trapped charge remaining after holding for $60 \mathrm{~s}$ across 100 iterations for randomly generated preheat values from $204-250{ }^{\circ} \mathrm{C}$ is shown for the $\mathrm{IRSL}_{50}(\mathrm{c})$ and post-IR $\operatorname{IRSL}_{225}(\mathrm{~d})$ signals. 


\section{This manuscript is a pre-print and has been submitted for publication in Quaternary Geochronology}

613 in the luminescence depth profiles of Experiment Ai in Figure 1 and cannot explain what is

614 observed.

615

616 On the basis of these results, and in agreement with the data of Murray et al. (2009), it is

617 difficult to reconcile our observations that differences in sample thermal treatment (Fig. 2) is

618 related to increased scatter of the IRSL data (Fig. 1). Nonetheless, we observe that sample

619 slices that have experienced different thermal treatments produce luminescence bleaching

620 profiles with more scatter (Fig. 2). Furthermore, IRSL signal decay differs between $10 \mathrm{~mm}$

621 diameter slices and $5 \mathrm{~mm}$ diameter slices of the same samples (Fig. 5), which TL data indicate

622 have experienced different heating conditions (Fig. 4), supporting the notion that the presence

623 of thermal lag must impact the IRSL emission in some way by reducing signal efficiency due

624 to reduced thermal assistance (cf. Hütt, 1988). Since feldspar is known to be highly thermally sensitive (e.g. Duller and Wintle, 1991), it is unsurprising that the IRSL $_{50}$ and post-IR IRSL 225

626 luminescence profiles demonstrate a greater improvement in noise reduction than that of

$627 \mathrm{OSL}_{125}$ in Figure 1. One potential source of the scatter may lie in the temperature dependence 628 of the infrared stimulated luminescence of feldspars (e.g. Duller and Bøtter-Jensen, 1993; 629 Poolton et al., 2002; Buylaert et al., 2009), and hence its sensitivity to the measurement 630 temperature which might not be consistent across one slice or from slice to slice, although this 631 is not sufficient to fully account for the observed scatter and would only partly contribute.

633 Whilst the physical process remains unclear, our data demonstrate that protocol modifications, 634 aimed at reducing variations in heating, result in less heterogeneous data (Fig. 1). As all the cores used in the measurement of the natural signal of GG18-05-01 are taken from the same

636 sample with the same exposure history, lithological variations cannot account for this 637 improvement (Fig. 1). Although variation in rates of anomalous fading or thermal stability 


\section{This manuscript is a pre-print and has been submitted for publication in Quaternary Geochronology}

could be considered as potential candidates for explaining variance in natural signals of the same sample, Lehmann et al. (2019) have demonstrated the effect of fading to be secondary to bleaching and Riedesel et al. (2019) have shown that the kinetic parameters of chemically different feldspars are similar. Finally, although differences in thermal treatment do not appear to affect subsequent IRSL emissions, TL plots remain useful in allowing the quantification of the degree of thermal lag that the samples are potentially experiencing, which can be done through calculating discrepancies in the experimental and modelled $110{ }^{\circ} \mathrm{C}$ peak positions.

\section{Implications for OSL rock surface dating}

The difference between luminescence profiles with depth (Fig. 1) measured using the protocols of Experiment $\mathrm{Ai}$ and Experiment Biii renders it immediately clear that applying the Experiment Biii protocol considerably reduces noise in the data, particularly for the IRSL $_{50}$ and post-IR IRSL 225 results. This improvement is supported by the TL signals (Fig. 2) and $\chi^{2}$ values. Core diameters can be chosen depending on the application of the study and lithology of the sample material.

The results from investigating the effect of slice diameter (Section 4.2.6, Fig. 6) imply that slice diameter is inconsequential to the results, and that the predominant factor is the placement of all rock slices in stainless steel cups. Both diameters used in this study (5 or $10 \mathrm{~mm}$ ) have their advantages. $5 \mathrm{~mm}$ diameter cores leave behind a smaller hole in the host rock, and so are potentially more suitable for archaeological studies that prefer to inflict minimal damage to the original material. However, their small diameter results in increased fragility and they are consequently more prone to breakage during sample preparation - namely coring and slicing. The small size of their slices also makes it challenging to accurately measure each slice's 


\section{This manuscript is a pre-print and has been submitted for publication in Quaternary Geochronology}

663 individual thicknesses, affecting depth reconstructions. In comparison, $10 \mathrm{~mm}$ diameter cores

664 are more robust during sample preparation and have slice thicknesses which are easier to 665 accurately measure. For heterogeneous lithologies, taking larger diameter cores is also 666 advantageous as this reduces the effect of spatial variations on a sample's measurement 667 reproducibly (Meyer et al., 2019). Each slice can subsequently be broken into several fragments 668 which can be measured separately to build a more comprehensive sample luminescence profile 669 with depth.

\subsection{Fit with surface exposure dating model}

672

673 Data from OSL surface exposure dating measurements can be fitted with a double exponential model that describes the time and depth dependent bleaching of minerals in rock surface dating 675 (Sohbati et al., 2011):

676

$677 \quad \frac{L x}{T x}(x, t)=L_{0} e^{-\overline{\sigma \varphi_{0}} t e^{-\mu x}}$

678

679 where $\frac{L x}{T x}$ is the normalised luminescence signal measured at depth $x(\mathrm{~mm})$ after exposure time $680 t(\mathrm{~s}) . L_{0}$ is the maximum luminescence signal intensity at saturation and assumed to have been 681 constant at all depths prior to daylight exposure. $\mu\left(\mathrm{cm}^{-1}\right)$ represents the light attenuation factor 682 and $\overline{\sigma \varphi_{0}}\left(\mathrm{~s}^{-1}\right)$ represents the decay rate of the luminescence signal at the bedrock surface. The 683 decay rate is assumed to be regionally uniform and is composed of the product of the 684 photoionisation cross section, $\sigma\left(\mathrm{cm}^{2}\right)$ and the photon flux, $\varphi_{0}\left(\mathrm{~cm}^{-2} \mathrm{~s}^{-1}\right)$.

686 The biggest challenge currently faced by surface exposure dating is the need to constrain $\overline{\sigma \varphi_{0}}$ 687 and $\mu$, as it is impossible to calculate an exposure age otherwise. These parameters have been 


\section{This manuscript is a pre-print and has been submitted for publication in Quaternary Geochronology}

688

689

690

691

692

693

694

695

696

697

698

699

700

701

702

703

704

705

706

707

708

709

710

711

shown to vary greatly across different lithologies, minerals and locations (e.g. Sohbati et al., 2012; Lehmann et al., 2018; Ou et al., 2018). One method of determining the values of these parameters is by local calibration from the luminescence profiles of independently known exposure age samples. The results can then be fed into the model to calculate unknown exposure ages, provided that the calibration and unknown samples are from the same region and lithology. Calibration surfaces can be found from a number of different sources - including historical records (Lehmann et al., 2018), road cut outcrops (Sohbati et al., 2012a) or the creation of a freshly exposed surface that can be resampled at a later date (Gliganic et al., 2019). To assess the implications of using different protocols on OSL surface exposure dating calculations, the latter calibration method was applied using calibration samples subjected to two different protocols. As mentioned in Section 3.1, a surface of unknown exposure age was sampled (GG17-05-01) and then a year later, an additional sample was taken (GG18-05-01) from the freshly exposed surface that had been created the previous year ( $342 \mathrm{~d}$ exposure age). Two luminescence profiles with depth were made for both GG17-05-01 and GG18-05-01 - one using the Experiment Ai protocol, with slices resting directly on the carousel, and the other using that of Experiment Biii, with a combination of $5 \mathrm{~mm}$ diameter slices and broken slices in the stainless steel cups. All luminescence profiles were made using at least 3 cores.

Using the two separate luminescence profiles for GG18-05-01, in combination with Eq. (1) and fixing a known exposure time $(t)$ of $0.936 \mathrm{a}$, we were able to invert for $\overline{\sigma \varphi_{0}}$ and $\mu$ values across all three signals. We then inverted for their respective protocol GG17-05-01 luminescence profile, but this time fixing the $\overline{\sigma \varphi_{0}}$ and $\mu$ values previously determined to calculate exposure ages. The inversions were done using a modified code from Lehmann et al. (2019), with $1 \times 10^{4}$ iterations to invert for the unknown parameters and $1 \times 10^{7}$ iterations for 
712 the exposure age. The results of these inversions are summarised in Table 5, with additional

713 detail in Table S7.

\begin{tabular}{c|ccc|ccc}
\hline $\begin{array}{c}\text { Protocol } \\
\text { applied }\end{array}$ & \multicolumn{3}{|c|}{ Experiment Ai } & \multicolumn{3}{c}{ Experiment Biii } \\
\hline & $\begin{array}{c}\mu \\
\left(\mathrm{mm}^{-1}\right)\end{array}$ & $\begin{array}{c}\overline{\sigma \varphi_{0}} \\
\left(\mathrm{a}^{-1}\right)\end{array}$ & $\begin{array}{c}\text { Exposure age } \\
(\mathrm{a})\end{array}$ & $\begin{array}{c}\mu \\
\left(\mathrm{mm}^{-1}\right)\end{array}$ & $\begin{array}{c}\overline{\sigma \varphi_{0}} \\
\left(\mathrm{a}^{-1}\right)\end{array}$ & $\begin{array}{c}\text { Exposure age } \\
(\mathrm{a})\end{array}$ \\
\hline IRSL $_{50}$ & 2.16 & 404.32 & $2.15 \pm 0.76$ & 1.19 & 12.65 & $2.94 \pm 0.25$ \\
\hline OSL $_{125}$ & 1.68 & 23.06 & $0.67 \pm 0.11$ & 1.70 & 10.17 & $3.36 \pm 0.65$ \\
\hline post-IR $_{\text {IRSL }_{225}}$ & 2.34 & 12.65 & $6.48 \pm 1.06$ & 1.60 & 4.90 & $3.42 \pm 0.63$ \\
\hline
\end{tabular}

Table 5: Results from fitting Equation 1 to luminescence depth profiles subjected to two different

protocols - Experiment Ai and Experiment Biii. The $\overline{\sigma \varphi_{0}}$ and $\mu$ values were initially constrained by fixing $t$

The exposure ages calculated using the improved protocol in Experiment Biii all lie within $1 \sigma$ also observe $\overline{\sigma \varphi_{0}}$ and $\mu$ values within similar orders of magnitude. In contrast, the exposure age results from using the protocol of Experiment Ai are more widespread, less precise and disagree at $2 \sigma$. These results highlight the importance of using an appropriate measurement invert the bleaching profile of sample GG17-05-01 measured using the protocol of Experiment $\mathrm{Ai}$, the ages are significantly overestimated, illustrating that it is essential to use the same measurement protocol for both calibration samples and measurement samples. 


\section{This manuscript is a pre-print and has been submitted for publication in Quaternary Geochronology}

732 As a result of the experiments in this study, it is recommended that a low heating rate and a

733 long isothermal hold (in this case $1^{\circ} \mathrm{C} \mathrm{s}^{-1}$ and $100 \mathrm{~s}$ respectively) are used (cf. Jenkins et al.,

734 2018) to allow the slices ample time to reach the desired temperature. Furthermore, all samples

735 should be placed in metal cups to improve thermal conductivity between the sample and heater

736 plate, and for these samples it is advantageous to have a sequence in which the post-IR IRSL 225

737 stimulation occurs prior to that of $\mathrm{OSL}_{125}$. However, as with all luminescence studies, it is the

738 responsibility of the luminescence practitioner to optimise their measurement protocol for their

739 specific aims and samples.

740

741

\section{Conclusion}

742

743 The results from this study show the influence of sample temperature on OSL surface exposure

744 dating measurements, as well as potential implications for age calculations if an unsuitable

745 protocol is used. It is usually assumed that samples heat to the temperature dictated by the measurement protocol. Here, however, we demonstrate that for $10 \mathrm{~mm}$ diameter rock slices placed directly on the reader carousel, this may not be the case. This thermal lag can result in anomalously high or low luminescence values, producing noisy luminescence profiles with depth, but the source of this scatter remains unclear. Since luminescence profiles with depth are instrumental to inverting for exposure ages, a noisy profile can affect age calculation. To minimise the effect of thermal lag, it is recommended to increase the isothermal holding time while decreasing the heating rate in the measurement protocol, and that all samples are placed in metal cups. These adjustments allow for the sample to heat at the desired rate and in a uniform manner.

\section{Acknowledgements}


758 This work was supported by the Swiss Government Excellence Scholarship (Award number

759 2017.1136). The authors would like to thank S. Vivero Andrade, D. Rech, C. Bouscary, A.

760 Ballu, L. Malatesta and G. Prasicek for fieldwork support, L. Bossin, R. Biswas and C. Schmidt

761 for laboratory support and stimulating discussions.

762

763

\section{References}

764

765

Aitken, M.J., 1985. Thermoluminescence Dating. Studies in Archaeological Science.

766

767 Aitken, M.J., 1998. An Introduction to Optical Dating: The Dating of Quaternary Sediments by the Use of Photon-Stimulated Luminescence. Oxford Science Publication.

769

770 Bailey, R.M., 2001. Towards a general kinetic model for optically and thermally stimulated 771 luminescence of quartz. Radiation Measurements, 33, 17-45.

772

773 Bøtter-Jensen, L., Thomsen, K.J., Jain, M., 2010. Review of optically stimulated luminescence

774 (OSL) instrumental developments for retrospective dosimetry. Radiation Measurements, 45, $253-257$.

776

777 Buylaert, J.P., Murray, A.S., Thomsen, K.J., Jain, M., 2009. Testing the potential of an elevated temperature IRSL signal from K-feldspar. Radiation Measurements, 44, 560-565.

779 
780 Chapot, M.S., Sohbati, R., Murray, A.S., Pederson, J.L., Rittenour, T.M., 2012. Constraining

781 the age of rock art by dating a rockfall event using sediment and rock-surface luminescence

782 dating techniques. Quaternary Geochronology, 13, 18-25.

783

784 Drury, M.J., 1987. Thermal diffusivity of some crystalline rocks. Geothermics, 16, 105-115.

785

786 Duller, G.A.T., Wintle, A.G., 1991. On infrared stimulated luminescence at elevated

787 temperatures. Nuclear Tracks and Radiation Measurements, 18, 379-384.

788

789 Duller, G.A.T., Bøtter-Jensen, L., 1993. Luminescence from potassium feldspars stimulated by

790 infrared and green light. Radiation Protection Dosimetry, 47, 683-688.

791

792 Duller, G.A.T., 2015. The Analyst software package for luminescence data: overview and 793 recent improvements. Ancient TL, 33, 35-42.

794

Duller, G.A.T., Roberts, H.M., Pinder, R.C., 2020. A method for routinely monitoring the reproducibility of thermal pretreatment prior to optically stimulated luminescence measurements. Radiation Measurements, 130, 106210.

798

799 Feathers, J., More, G.M., Quinteros, P.S., Burkholder, J.E., 2019. IRSL dating of rocks and 800 sediments from desert geoglyphs in coastal Peru. Quaternary Geochronology, 49, 177-183.

801

802 Freiesleben, T., Sohbati, R., Murray, A.S., Jain, M., al Khasawneh, S., Hvidt, S., Jakobsen, B., 803 2015. Mathematical model quantifies multiple daylight exposure and burial events for rock 804 surfaces using luminescence dating. Radiation Measurements, 81, 16-22. 
806 Friedrich, J., Kreutzer, S., Schmidt, C., 2016. Solving ordinary differential equations to

807 understand luminescence: 'RLumModel', an advanced research tool for simulating

808 luminescence in quartz using R. Quaternary Geochronology, 35, 88-100.

809

810 Gliganic, L.A., Meyer, M.C., Sohbati, R., Jain, M., Barrett, S., 2019. OSL surface exposure

811 dating of a lithic quarry in Tibet: Laboratory validation and application. Quaternary

812 Geochronology, 49, 199-204.

813

814 Habermann, J., Schilles, T., Kalchgruber, R., Wagner, G.A., 2000. Steps towards surface

815 dating using luminescence. Radiation Measurements, 32, 847- 851.

816

817 Huntley, D.J., McMullan, W.G., Godfrey-Smith, D.I., Thewalt, M.L.W., 1989. Time-

818 dependent recombination spectra arising from optical ejection of trapped charges in feldspars.

819 Journal of Luminescence, 44, 41- 46.

820

821 Hütt, G., Jaek, I., Tchonka, J., 1988. Optical dating: potassium feldspars optical response 822 stimulation spectra. Quaternary Science Reviews, 7, 381-385.

823

824 Jain, M., Bøtter-Jensen, L., Murray, A.S., Essery, R., 2007. A peak structure in isothermal 825 luminescence signals in quartz: origin and implications. Journal of Luminescence, 127, 678826 688. 
828 Jenkins, G.T.H., Duller, G.A.T., Roberts, H.M., Chiverrell, R.C., Glasser, N.F., 2018. A new 829 approach for luminescence dating glaciofluvial deposits- high precision optical dating of 830 cobbles. Quaternary Science Reviews, 192, 263-273.

831

832 Kars, R.H., Reimann, T., Wallinga, J., 2014. Are feldspar SAR protocols appropriate for post-

833 IR IRSL dating? Quaternary Geochronology, 22, 126-136.

834

835 King, G.E., Herman, F., Lambert, R., Valla, P.G., Guralnik, B., 2016. Multi-OSL836 thermochronometry of feldspar. Quaternary Geochronology, 33, 76-87.

837

838 al Khasawneh, S., Murray, A.S., Thomsen, K., Abu-Azizeh, W., Tawawneh, M., 2018. Dating a near eastern desert hunting trap (kite) using rock surface luminescence dating. Archaeological and Anthropological Sciences.

Laskaris, N., Liritzis, I., 2011. A new mathematical approximation of sunlight attenuation in rocks for surface luminescence dating. Journal of Luminescence, 131, 1874- 1884.

849 Lehmann, B., Valla, P.G., King, G.E., Herman, F., 2018. Investigation of OSL surface exposure dating to reconstruct post-LIA glacier fluctuations in the French Alps (Mer de Glace,

851 Mont Blanc massif), Quaternary Geochronology, 44, 64-74. 


\section{This manuscript is a pre-print and has been submitted for publication in Quaternary Geochronology}

853 Lehmann, B., Herman, F., Valla, P.G., King, G.E., Biswas, R.H., 2019. Evaluating post-glacial

854 bedrock erosion and surface exposure duration by coupling in-situ OSL and ${ }^{10} \mathrm{Be}$ dating. Earth

855 Surface Dynamics, 7, 633-662.

856

857 Lehmann, B., Herman, F., Valla, P.G., King, G.E., Biswas, R.H., Ivy-Ochs, S., Steinemann,

O., Christl, M., 2020. Postglacial erosion of bedrock surfaces and deglaciation timing: New insights from the Mont Blanc massif(Western Alps). Geology, 48(2), 139-144/

860

Li, B., Li, S.H., 2013. The effect of band-tail states on the thermal stability of the infrared

862 stimulated luminescence from K-feldspar. Journal of Luminescence, 136, 5-10.

863

Liu, J., Cui, F., Murray, A.S., Sohbati, R., Jain, M., Gao, H., Li, W., Li, C., Li, P., Zhou, T.,

Chen, J., 2019. Resetting of the luminescence signal in modern riverbed cobbles along the course of the Shiyang River, China. Quaternary Geochronology, 49, 184-190.

867

868 Luo, M., Chen, J., Liu, J., Qin, J., Owen, L.A., Han, F., Yang, H., Wang, H., Zhang, B., Yin, J., Li, Y., 2018. A test of rock surface luminescence dating using glaciofluvial boulders from the Chinese Pamir. Radiation Measurements, 120, 290-297.

872 Liritzis, I., 1994. A new dating method by thermoluminscence of carved megalithic stone

873 building. Comptes Rendus Académie des Science Paris, 319 (série II), 603-610.

874

875 Liritzis, I., Vafiadou, A., 2015. Surface luminescence dating of some Egyptian monuments.

876 Journal of Cultural Heritage, 16, 134-150. 
878 Meyer, M.C., Gliganic, L.A., Jain, M., Sohbati, R., Schmidmair, D., 2018. Lithological 879 controls on light penetration into rock surfaces- Implications for OSL and IRSL surface

880 exposure dating. Radiation Measurements, 120, 298-304.

881

882 Murray, A.S., Wintle, A.G., 2000. Luminescence dating of quartz using an improved single

883 aliquot regenerative-dose protocol. Radiation Measurements, 32, 57-73.

884

885 Murray, A.S., Buylaert, J.P., Thomsen, K.J., Jain, M., 2009. The effect of preheating on the 886 IRSL signal from feldspar. Radiation Measurements, 44, 554-559.

887

888 Ou, X.J., Roberts, H.M., Duller, G.A.T., Gunn, M.D., Perkins, W.T., 2018. Attenuation of light 889 in different rock types and implications for rock surface luminescence dating. Radiation 890 Measurements, 120, 305-311.

891

892 Pagonis, V., Kitis, G., Chen, R., 2003. Applicability of the Zimmerman predose model in the 893 thermoluminescence of predosed and annealed synthetic quartz samples. Radiation 894 Measurements, 37, 267-274.

895

896 Polikreti, K., Michael, C., Maniatis, Y., 2002. Authenticating marble sculptures with 897 thermoluminescence. Ancient TL, 20, 11-18.

898

899 Polikreti, K., Michael, C.T., Maniatis, Y., 2003. Thermoluminescence characteristics of marble 900 and dating of freshly excavated marble objects. Radiation Measurements, 37, 87-94. 


\section{This manuscript is a pre-print and has been submitted for publication in Quaternary Geochronology}

902 Poolton, N.R.J., Ozanyan, K.B., Wallinga, J., Murray, A.S., Bøtter-Jensen, L., 2002. Electrons

903 in feldspar II: a consideration of the influence of conduction band-tail states on luminescence

904 processes. Physics and Chemistry of Minerals, 29, 217-225.

905

906 Rades, E.F., Sohbati, R., Lüthgens, C., Jain, M., Murray, A.S., 2018. First luminescence-depth

907 profiles from boulders from moraine deposits: Insights into glaciation chronology and transport

908 dynamics in Malta valley, Austria. Radiation Measurements, 120, 281-289.

909

910 Reimann, T., Notenboom, P.D., De Schipper, M.A., Wallinga, J., 2015. Testing for sufficient

911 signal resetting during sediment transport using a polymineral multiple-signal luminescence

912 approach. Quaternary Geochronology, 25, 26-36.

913

914 Rhodes, E.J., 2011. Optically stimulated luminescence dating of sediments over the past 915 200,000 years. Annual Review Earth Planetary Sciences, 39, 461-488.

916

917 Richards, M., 1994. Luminescence dating of quartzite from the Diring Yuriakh site. Thesis, 918 Simon Fraser University, August 1994.

919

920 Riedesel, S., King, G.E., Prasad, A.K., Kumar, R., Finch, A.A., Jain, M., 2019. Optical 921 determination of the width of the band-tail states, and the excited and ground state energies of 922 the principal dosimetric trap in feldspar. Radiation Measurements, 125, 40-51.

923

924 Schmidt, C., Friedrich, J., Adamiec, G., Chruścińska, A., Fasoli, M., Kreutzer, S., Martini, M.,

925 Panzeri, L., Polymeris, G.S., Przegiętka, K., Valla, P.G., King, G.E., Sanderson, D.C.W., 2018. 


\section{This manuscript is a pre-print and has been submitted for publication in Quaternary Geochronology}

926 How reproducible are kinetic parameter constraints of quartz luminescence? An interlaboratory

927

928

929 Simkins, L.M., Simms, A.R., DeWitt, R., 2013. Relative sea level history of Marguerite Bay,

930 Antarctic Peninsula, derived from optically stimulated luminescence dated beach cobbles.

931 Quaternary Science Reviews, 77, 141-155.

932

933

934

935

936

937 Simms, A.R., Ivins, E.R., DeWitt, R., Kouremenos, P., Simkins, L.M., 2012. Timing of the

938

939

940

941

942

943

944

945 Sohbati, R., Murray, A.S., Chapot, M.S., Jain, M., Pederson, J., 2012a. Optically stimulated

946 luminescence (OSL) as a chronometer for surface exposure dating. Journal of Geophysical

947 Research: Solid Earth, 117, B09202. 
949 Sohbati, R., Murray, A.S., Buylaert, J.-P., Almeida, N.A.C., Cunha, P.P., 2012b. Optically

950 stimulated luminescence (OSL) dating of quartzite cobbles from the Tapada do Montinho

951 archaeological site (east-central Portugal). Boreas, 41, 452-462.

952

953 Sohbati, R., Murray, A.S., Jain, M., Avner, U, 2015. Age of a prehistoric "Rodedian” cult site

954 constrained by sediment and rock surface dating techniques. Quaternary Geochronology, 30, $95590-99$.

956

957 Sohbati R., Liu, J., Jain, M., Egholm, D., Paris, R., Guralnik, B., 2018. Centennial-to millennia958 scale hard rock erosion rates deduced from luminescence-depth profiles. Earth and Planetary 959 Science Letters, 493, 218-230.

960

961 Souza, P.E., Sohbati, R., Murray, A.S., Kroon, A., Clemmensen, L.B., Hede, M.U., Nielsen,

962 L., 2019. Luminescence dating of buried cobble surfaces from sandy beach ridges: a case study 963 from Denmark. Boreas.

964

965 Theocaris, P.S., Liritzis, I., Galloway, R.B., 1997. Dating of two Hellenic Pyramids by a novel 966 application of thermoluminescence. Journal of Archaeological Science, 24, 399-405. 

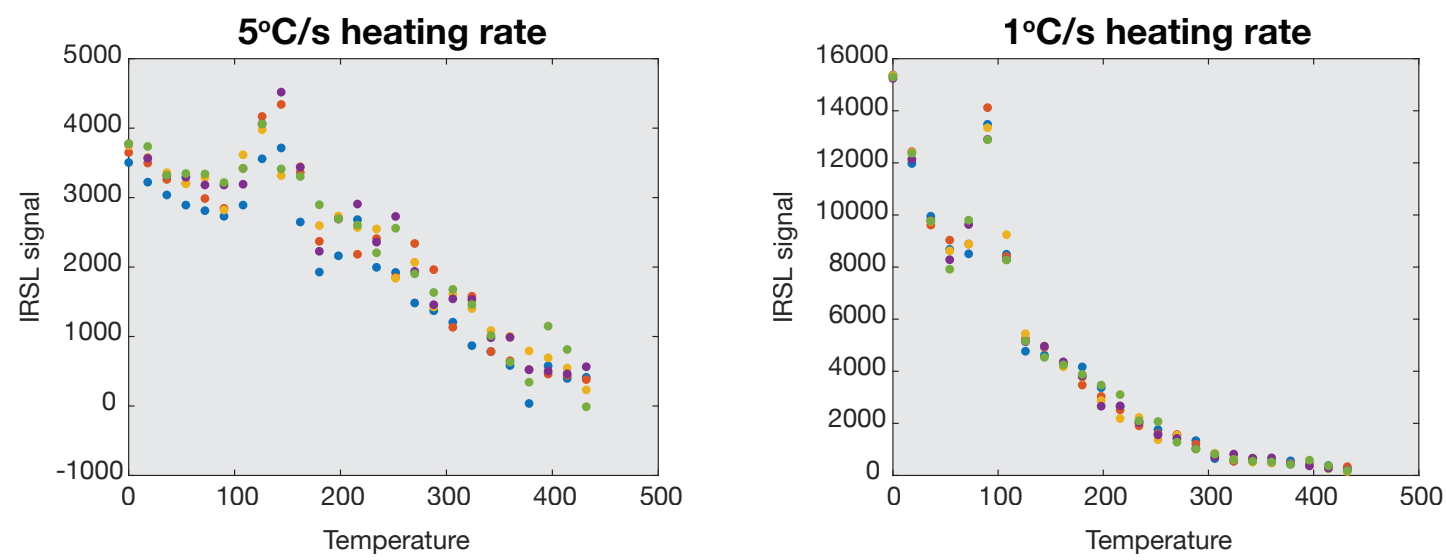

- Cycle $1 \cdot$ Cycle $2 \cdot$ Cycle $3 \cdot$ Cycle $4 \cdot$ Cycle 5

Figure S1: IRSL signal detected during a TOL measurement on a $10 \mathrm{~mm}$ diameter slice resting directly on the carousel. The slice was ramped up to $450^{\circ} \mathrm{C}$ and measured 5 times for reproducibility purposes (termed cycles).

969
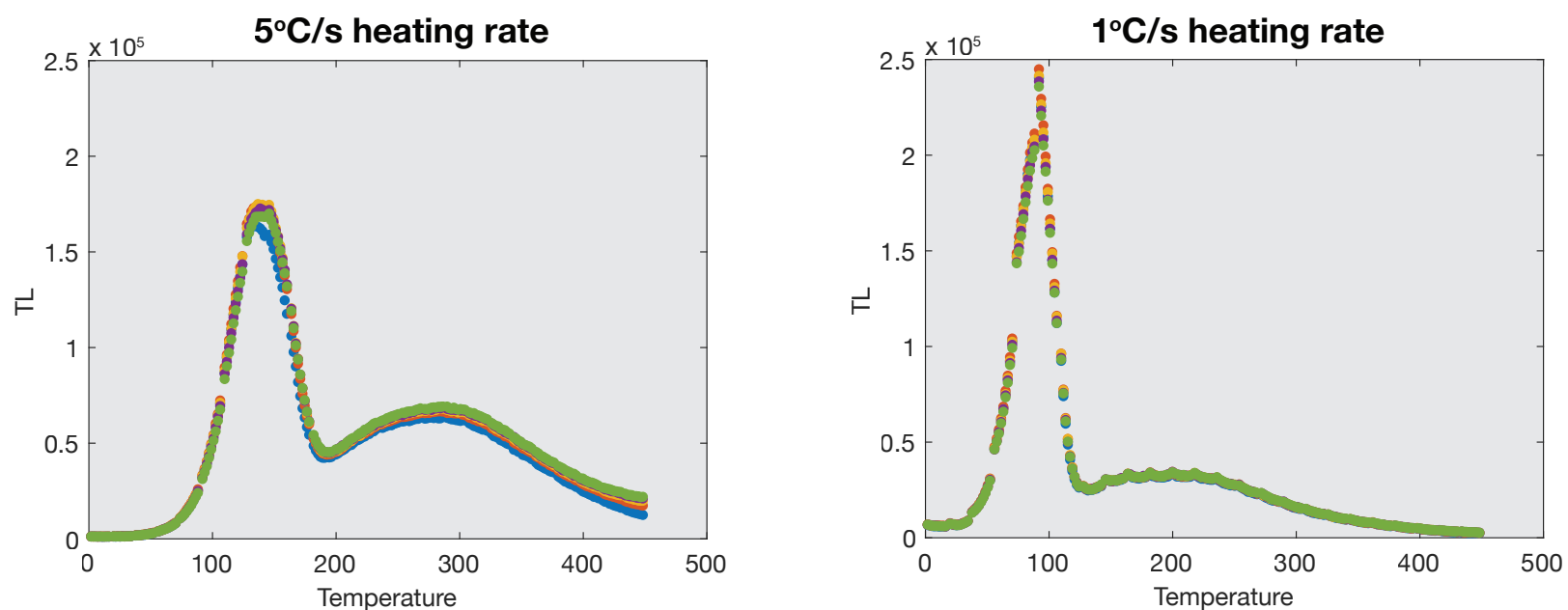

- Cycle $1 \cdot$ Cycle $2 \cdot$ Cycle $3 \cdot$ Cycle $4 \cdot$ Cycle 5

970 Figure S2: TL curves obtained during the TOL measurement (Section 6) on a $10 \mathrm{~mm}$ diameter slice resting directly on the carousel. The slice was ramped up to $450^{\circ} \mathrm{C}$ and measured 5 times for reproducibility purposes. 
Gepethrenokgigy

\begin{tabular}{cccccc}
\hline Stimulation & Filter & Heating rate $\left({ }^{\circ} \mathrm{C} \mathrm{s}^{-1}\right)$ & Isothermal hold (s) & Signal & Target mineral \\
\hline $\begin{array}{c}\text { Regenerative dose } \\
51.75 \mathrm{~Gy}\end{array}$ & & & & \\
$\begin{array}{c}\text { Preheat to } 250^{\circ} \mathrm{C} \\
\text { IRSL at } 50^{\circ} \mathrm{C}\end{array}$ & $\mathrm{U} 340$ & 5 & 60 & & \\
OSL at $125^{\circ} \mathrm{C}$ & $\mathrm{U} 340$ & 5 & 5 & $\mathrm{IRSL}_{50} L_{x}$ & Feldspar \\
IRSL at $225^{\circ} \mathrm{C}$ & $\mathrm{U} 340$ & 5 & 5 & $\mathrm{OSL}_{125} L_{x}$ & Quartz \\
post-IR & Feldspar \\
Test dose $51.75 \mathrm{~Gy}$ & $\mathrm{U} 340$ & 5 & 5 & & \\
Preheat to $250^{\circ} \mathrm{C}$ & $\mathrm{U} 340$ & & & \\
IRSL at $50^{\circ} \mathrm{C}$ & $\mathrm{U} 340$ & 5 & 60 & & \\
OSL at $125^{\circ} \mathrm{C}$ & $\mathrm{U} 340$ & 5 & 5 & $\mathrm{IRSL}_{50} T_{x}$ & Feldspar \\
IRSL at $225^{\circ} \mathrm{C}$ & $\mathrm{U} 340$ & 5 & 5 & $\mathrm{OSL}_{125} T_{x}$ & Quartz \\
\hline \multicolumn{2}{c}{ Rest-IR } & Feldspar \\
\hline
\end{tabular}

Experiment A(ii)

\begin{tabular}{|c|c|c|c|c|c|}
\hline Stimulation & Filter & Heating rate $\left({ }^{\circ} \mathrm{C} \mathrm{s}^{-1}\right)$ & Isothermal hold (s) & Signal & Target mineral \\
\hline \multicolumn{6}{|l|}{$\begin{array}{c}\text { Regenerative dose } \\
51.75 \mathrm{~Gy}\end{array}$} \\
\hline Preheat to $250^{\circ} \mathrm{C}$ & $\mathrm{BG} 39+\mathrm{BG} 3$ & 5 & 60 & & \multirow{4}{*}{$\begin{array}{c}\text { Feldspar } \\
\text { Quartz } \\
\text { Feldspar }\end{array}$} \\
\hline IRSL at $50^{\circ} \mathrm{C}$ & $\mathrm{BG} 39+\mathrm{BG} 3$ & 5 & 5 & $\operatorname{IRSL}_{50} L_{x}$ & \\
\hline $\mathrm{OSL}$ at $125^{\circ} \mathrm{C}$ & U340 & 5 & 5 & $\begin{array}{c}\mathrm{OSL}_{125} L_{x} \\
\text { post-IR }\end{array}$ & \\
\hline IRSL at $225^{\circ} \mathrm{C}$ & $\mathrm{BG} 39+\mathrm{BG} 3$ & 5 & 5 & $\mathrm{IRSL}_{225} L_{x}$ & \\
\hline \multicolumn{6}{|l|}{ Test dose 51.75 Gy } \\
\hline Preheat to $250^{\circ} \mathrm{C}$ & $\mathrm{BG} 39+\mathrm{BG} 3$ & 5 & 60 & & \multirow{4}{*}{$\begin{array}{c}\text { Feldspar } \\
\text { Quartz } \\
\text { Feldspar }\end{array}$} \\
\hline IRSL at $50^{\circ} \mathrm{C}$ & $\mathrm{BG} 39+\mathrm{BG} 3$ & 5 & 5 & $\operatorname{IRSL}_{50} T_{x}$ & \\
\hline $\mathrm{OSL}$ at $125^{\circ} \mathrm{C}$ & U340 & 5 & 5 & $\begin{array}{c}\mathrm{OSL}_{125} T_{x} \\
\text { post-IR }\end{array}$ & \\
\hline IRSL at $225^{\circ} \mathrm{C}$ & $\mathrm{BG} 39+\mathrm{BG} 3$ & 5 & 5 & $\begin{array}{l}\text { IRSL } \\
\text { IRS2 }_{2} T_{x}\end{array}$ & \\
\hline
\end{tabular}

Experiment A(iii)

\begin{tabular}{|c|c|c|c|c|c|}
\hline \multicolumn{6}{|c|}{ Experiment A(iii) } \\
\hline Stimulation & Filter & Heating rate $\left({ }^{\circ} \mathrm{C} \mathrm{s}^{-1}\right)$ & Isothermal hold (s) & Signal & Target mineral \\
\hline $\begin{array}{c}\text { Regenerative dose } \\
51.75 \mathrm{~Gy}\end{array}$ & & & & & \\
\hline Preheat to $250^{\circ} \mathrm{C}$ & $\mathrm{BG} 39+\mathrm{BG} 3$ & 5 & 60 & & \\
\hline IRSL at $50^{\circ} \mathrm{C}$ & $\mathrm{BG} 39+\mathrm{BG} 3$ & 5 & 5 & $\operatorname{IRSL}_{50} L_{x}$ & Feldspar \\
\hline IRSL at $225^{\circ} \mathrm{C}$ & $\mathrm{BG} 39+\mathrm{BG} 3$ & 5 & 5 & $\mathrm{OSL}_{125} L_{x}$ & Quartz \\
\hline OSL at $125^{\circ} \mathrm{C}$ & U340 & 5 & 5 & $\operatorname{IRSL}_{225} L_{x}$ & Feldspar \\
\hline Test dose 51.75 Gy & & & & & \\
\hline Preheat to $250^{\circ} \mathrm{C}$ & $\mathrm{BG} 39+\mathrm{BG} 3$ & 5 & 60 & & \\
\hline IRSL at $50^{\circ} \mathrm{C}$ & $\mathrm{BG} 39+\mathrm{BG} 3$ & 5 & 5 & $\operatorname{IRSL}_{50} T_{x}$ & Feldspar \\
\hline IRSL at $225^{\circ} \mathrm{C}$ & $\mathrm{BG} 39+\mathrm{BG} 3$ & 5 & 5 & $\mathrm{OSL}_{125} T_{x}$ & Quartz \\
\hline $\mathrm{OSL}$ at $125^{\circ} \mathrm{C}$ & U340 & 5 & 5 & $\operatorname{IRSL}_{225} T_{x}$ & Feldspar \\
\hline
\end{tabular}


This manuscript is a pre-print and has been submitted for publication in Quaternary Geochronology

971

Repeat 5 times

972 Table S1: Measurement protocol for the three parts of Experiment A. 


\section{Gebexprimentbg(i)}

\begin{tabular}{|c|c|c|c|c|c|}
\hline Stimulation & Filter & Heating rate $\left({ }^{\circ} \mathrm{C} \mathrm{s}^{-1}\right)$ & Isothermal hold (s) & Signal & Target mineral \\
\hline \multicolumn{6}{|l|}{$\begin{array}{c}\text { Regenerative dose } \\
51.75 \mathrm{~Gy}\end{array}$} \\
\hline Preheat to $250^{\circ} \mathrm{C}$ & U340 & 1 & 100 & & \multirow{4}{*}{$\begin{array}{c}\text { Feldspar } \\
\text { Quartz } \\
\text { Feldspar }\end{array}$} \\
\hline IRSL at $50^{\circ} \mathrm{C}$ & U340 & 1 & 100 & $\operatorname{IRSL}_{50} L_{x}$ & \\
\hline OSL at $125^{\circ} \mathrm{C}$ & U340 & 1 & 100 & $\begin{array}{c}\mathrm{OSL}_{125} L_{x} \\
\text { post-IR }\end{array}$ & \\
\hline IRSL at $225^{\circ} \mathrm{C}$ & U340 & 1 & 100 & $\operatorname{IRSL}_{225} L_{x}$ & \\
\hline \multicolumn{6}{|l|}{ Test dose $51.75 \mathrm{~Gy}$} \\
\hline Preheat to $250^{\circ} \mathrm{C}$ & U340 & 1 & 100 & & \multirow{4}{*}{$\begin{array}{c}\text { Feldspar } \\
\text { Quartz } \\
\text { Feldspar }\end{array}$} \\
\hline IRSL at $50^{\circ} \mathrm{C}$ & U340 & 1 & 100 & $\operatorname{IRSL}_{50} T_{x}$ & \\
\hline $\mathrm{OSL}$ at $125^{\circ} \mathrm{C}$ & U340 & 1 & 100 & $\begin{array}{c}\mathrm{OSL}_{125} T_{x} \\
\text { post-IR }\end{array}$ & \\
\hline IRSL at $225^{\circ} \mathrm{C}$ & $\mathrm{U} 340$ & 1 & 100 & $\mathrm{IRSL}_{225} T_{x}$ & \\
\hline \multicolumn{6}{|c|}{ Repeat 5 times } \\
\hline \multicolumn{6}{|c|}{ Experiment B(ii) } \\
\hline Stimulation & Filter & Heating rate $\left({ }^{\circ} \mathrm{C} \mathrm{s}^{-1}\right)$ & Isothermal hold (s) & Signal & Target mineral \\
\hline \multicolumn{6}{|l|}{$\begin{array}{c}\text { Regenerative dose } \\
51.75 \mathrm{~Gy}\end{array}$} \\
\hline Preheat to $250^{\circ} \mathrm{C}$ & $\mathrm{BG} 39+\mathrm{BG} 3$ & 1 & 100 & & \multirow{4}{*}{$\begin{array}{c}\text { Feldspar } \\
\text { Quartz } \\
\text { Feldspar }\end{array}$} \\
\hline IRSL at $50^{\circ} \mathrm{C}$ & $\mathrm{BG} 39+\mathrm{BG} 3$ & 1 & 100 & $\operatorname{IRSL}_{50} L_{x}$ & \\
\hline $\mathrm{OSL}$ at $125^{\circ} \mathrm{C}$ & U340 & 1 & 100 & $\mathrm{OSL}_{125} L_{x}$ & \\
\hline IRSL at $225^{\circ} \mathrm{C}$ & BG39+ BG3 & 1 & 100 & $\begin{array}{l}\text { post-IR } \\
\text { IRSL }_{225} L_{x}\end{array}$ & \\
\hline \multicolumn{6}{|l|}{ Test dose $51.75 \mathrm{~Gy}$} \\
\hline Preheat to $250^{\circ} \mathrm{C}$ & $\mathrm{BG} 39+\mathrm{BG} 3$ & 1 & 100 & & \multirow{4}{*}{$\begin{array}{c}\text { Feldspar } \\
\text { Quartz } \\
\text { Feldspar }\end{array}$} \\
\hline IRSL at $50^{\circ} \mathrm{C}$ & $\mathrm{BG} 39+\mathrm{BG} 3$ & 1 & 100 & $\operatorname{IRSL}_{50} T_{x}$ & \\
\hline OSL at $125^{\circ} \mathrm{C}$ & U340 & 1 & 100 & $\begin{array}{c}\mathrm{OSL}_{125} T_{x} \\
\text { post-IR }\end{array}$ & \\
\hline IRSL at $225^{\circ} \mathrm{C}$ & $\mathrm{BG} 39+\mathrm{BG} 3$ & 1 & 100 & $\mathrm{IRSL}_{225} T_{x}$ & \\
\hline \multicolumn{6}{|c|}{ Repeat 5 times } \\
\hline \multicolumn{6}{|c|}{ Experiment B(iii) } \\
\hline Stimulation & Filter & Heating rate $\left({ }^{\circ} \mathrm{C} \mathrm{s}^{-1}\right)$ & Isothermal hold (s) & Signal & Target mineral \\
\hline \multicolumn{6}{|l|}{$\begin{array}{c}\text { Regenerative dose } \\
51.75 \mathrm{~Gy}\end{array}$} \\
\hline Preheat to $250^{\circ} \mathrm{C}$ & $\mathrm{BG} 39+\mathrm{BG} 3$ & 1 & 100 & & \multirow{4}{*}{$\begin{array}{c}\text { Feldspar } \\
\text { Quartz } \\
\text { Feldspar }\end{array}$} \\
\hline IRSL at $50^{\circ} \mathrm{C}$ & $\mathrm{BG} 39+\mathrm{BG} 3$ & 1 & 100 & $\operatorname{IRSL}_{50} L_{x}$ & \\
\hline IRSL at $225^{\circ} \mathrm{C}$ & $\mathrm{BG} 39+\mathrm{BG} 3$ & 1 & 100 & $\begin{array}{c}\mathrm{OSL}_{125} L_{x} \\
\text { post-IR }\end{array}$ & \\
\hline OSL at $125^{\circ} \mathrm{C}$ & U340 & 1 & 100 & $\begin{array}{l}\text { post-IR } \\
\text { IRSL }_{225} L_{x}\end{array}$ & \\
\hline \multicolumn{6}{|l|}{ Test dose 51.75 Gy } \\
\hline Preheat to $250^{\circ} \mathrm{C}$ & $\mathrm{BG} 39+\mathrm{BG} 3$ & 1 & 100 & & \multirow{4}{*}{$\begin{array}{c}\text { Feldspar } \\
\text { Quartz } \\
\text { Feldspar }\end{array}$} \\
\hline IRSL at $50^{\circ} \mathrm{C}$ & $\mathrm{BG} 39+\mathrm{BG} 3$ & 1 & 100 & $\operatorname{IRSL}_{50} T_{x}$ & \\
\hline IRSL at $225^{\circ} \mathrm{C}$ & $\mathrm{BG} 39+\mathrm{BG} 3$ & 1 & 100 & $\begin{array}{c}\mathrm{OSL}_{125} T_{x} \\
\text { post-IR }\end{array}$ & \\
\hline $\mathrm{OSL}$ at $125^{\circ} \mathrm{C}$ & U340 & 1 & 100 & $\operatorname{IRSL}_{225} T_{x}$ & \\
\hline
\end{tabular}


This manuscript is a pre-print and has been submitted for publication in Quaternary Geochronology

973 Repeat 5 times

974 Table S2: Measurement protocol for the three parts of Experiment B. 


\section{GÉËhrimgnt G(i)}

\begin{tabular}{|c|c|c|c|c|c|}
\hline Stimulation & Filter & Heating rate $\left({ }^{\circ} \mathrm{C} \mathrm{s}^{-1}\right)$ & Isothermal hold (s) & Signal & Target mineral \\
\hline \multicolumn{6}{|l|}{$\begin{array}{c}\text { Regenerative dose } \\
51.75 \mathrm{~Gy}\end{array}$} \\
\hline Preheat to $250^{\circ} \mathrm{C}$ & U340 & 1 & 60 & & \multirow{4}{*}{$\begin{array}{c}\text { Feldspar } \\
\text { Quartz } \\
\text { Feldspar }\end{array}$} \\
\hline IRSL at $50^{\circ} \mathrm{C}$ & U340 & 1 & 5 & $\operatorname{IRSL}_{50} L_{x}$ & \\
\hline OSL at $125^{\circ} \mathrm{C}$ & U340 & 1 & 5 & $\begin{array}{c}\mathrm{OSL}_{125} L_{x} \\
\text { post-IR }\end{array}$ & \\
\hline IRSL at $225^{\circ} \mathrm{C}$ & U340 & 1 & 5 & $\operatorname{IRSL}_{225} L_{x}$ & \\
\hline \multicolumn{6}{|l|}{ Test dose $51.75 \mathrm{~Gy}$} \\
\hline Preheat to $250^{\circ} \mathrm{C}$ & U340 & 1 & 60 & & \multirow{4}{*}{$\begin{array}{c}\text { Feldspar } \\
\text { Quartz } \\
\text { Feldspar }\end{array}$} \\
\hline IRSL at $50^{\circ} \mathrm{C}$ & U340 & 1 & 5 & $\operatorname{IRSL}_{50} T_{x}$ & \\
\hline OSL at $125^{\circ} \mathrm{C}$ & U340 & 1 & 5 & $\begin{array}{c}\mathrm{OSL}_{125} T_{x} \\
\text { post-IR }\end{array}$ & \\
\hline IRSL at $225^{\circ} \mathrm{C}$ & U340 & 1 & 5 & $\mathrm{IRSL}_{225} T_{x}$ & \\
\hline \multicolumn{6}{|c|}{ Repeat 5 times } \\
\hline \multicolumn{6}{|c|}{ Experiment C(ii) } \\
\hline Stimulation & Filter & Heating rate $\left({ }^{\circ} \mathrm{C} \mathrm{s}^{-1}\right)$ & Isothermal hold (s) & Signal & Target mineral \\
\hline \multicolumn{6}{|l|}{$\begin{array}{c}\text { Regenerative dose } \\
51.75 \mathrm{~Gy}\end{array}$} \\
\hline Preheat to $250^{\circ} \mathrm{C}$ & BG39 + BG3 & 1 & 60 & & \multirow{4}{*}{$\begin{array}{c}\text { Feldspar } \\
\text { Quartz } \\
\text { Feldspar }\end{array}$} \\
\hline IRSL at $50^{\circ} \mathrm{C}$ & BG39 + BG3 & 1 & 5 & $\mathrm{IRSL}_{50} L_{x}$ & \\
\hline $\mathrm{OSL}$ at $125^{\circ} \mathrm{C}$ & U340 & 1 & 5 & $\mathrm{OSL}_{125} L_{x}$ & \\
\hline IRSL at $225^{\circ} \mathrm{C}$ & BG39 + BG3 & 1 & 5 & $\begin{array}{l}\text { post-1R } \\
\text { IRSL }_{225} L_{x}\end{array}$ & \\
\hline \multicolumn{6}{|l|}{ Test dose $51.75 \mathrm{~Gy}$} \\
\hline Preheat to $250^{\circ} \mathrm{C}$ & $\mathrm{BG} 39+\mathrm{BG} 3$ & 1 & 60 & & \multirow{4}{*}{$\begin{array}{c}\text { Feldspar } \\
\text { Quartz } \\
\text { Feldspar }\end{array}$} \\
\hline IRSL at $50^{\circ} \mathrm{C}$ & BG39 + BG3 & 1 & 5 & $\mathrm{IRSL}_{50} T_{x}$ & \\
\hline $\mathrm{OSL}$ at $125^{\circ} \mathrm{C}$ & U340 & 1 & 5 & $\begin{array}{c}\mathrm{OSL}_{125} T_{x} \\
\text { post-IR }\end{array}$ & \\
\hline IRSL at $225^{\circ} \mathrm{C}$ & $\mathrm{BG} 39+\mathrm{BG} 3$ & 1 & 5 & $\mathrm{IRSL}_{225} T_{x}$ & \\
\hline \multicolumn{6}{|c|}{ Repeat 5 times } \\
\hline \multicolumn{6}{|c|}{ Experiment C(iii) } \\
\hline Stimulation & Filter & Heating rate $\left({ }^{\circ} \mathrm{C} \mathrm{s}^{-1}\right)$ & Isothermal hold (s) & Signal & Target mineral \\
\hline \multicolumn{6}{|l|}{$\begin{array}{c}\text { Regenerative dose } \\
51.75 \mathrm{~Gy}\end{array}$} \\
\hline Preheat to $250^{\circ} \mathrm{C}$ & BG39 + BG3 & 1 & 60 & & \multirow{4}{*}{$\begin{array}{c}\text { Feldspar } \\
\text { Quartz } \\
\text { Feldspar }\end{array}$} \\
\hline IRSL at $50^{\circ} \mathrm{C}$ & BG39 + BG3 & 1 & 5 & $\operatorname{IRSL}_{50} L_{x}$ & \\
\hline IRSL at $225^{\circ} \mathrm{C}$ & BG39 + BG3 & 1 & 5 & $\mathrm{OSL}_{125} L_{x}$ & \\
\hline OSL at $125^{\circ} \mathrm{C}$ & U340 & 1 & 5 & $\begin{array}{c}\text { post-IR } \\
\text { IRSL }_{225} L_{x}\end{array}$ & \\
\hline \multicolumn{6}{|l|}{ Test dose 51.75 Gy } \\
\hline Preheat to $250^{\circ} \mathrm{C}$ & BG39 + BG3 & 1 & 60 & & \multirow{4}{*}{$\begin{array}{c}\text { Feldspar } \\
\text { Quartz } \\
\text { Feldspar }\end{array}$} \\
\hline IRSL at $50^{\circ} \mathrm{C}$ & BG39 + BG3 & 1 & 5 & $\operatorname{IRSL}_{50} T_{x}$ & \\
\hline IRSL at $225^{\circ} \mathrm{C}$ & BG39 + BG3 & 1 & 5 & $\begin{array}{c}\mathrm{OSL}_{125} T_{x} \\
\text { post-IR }\end{array}$ & \\
\hline $\mathrm{OSL}$ at $125^{\circ} \mathrm{C}$ & U340 & 1 & 5 & $\mathrm{IRSL}_{225} T_{x}$ & \\
\hline
\end{tabular}


This manuscript is a pre-print and has been submitted for publication in Quaternary Geochronology

976 Table S3: Measurement protocol for the three parts of Experiment C. 


\begin{tabular}{|c|c|c|c|c|c|}
\hline Stimulation & Filter & Heating rate $\left({ }^{\circ} \mathrm{C} \mathrm{s}^{-1}\right)$ & Isothermal hold (s) & Signal & Target mineral \\
\hline \multicolumn{6}{|l|}{$\begin{array}{c}\text { Regenerative dose } \\
51.75 \mathrm{~Gy}\end{array}$} \\
\hline Preheat to $250^{\circ} \mathrm{C}$ & U340 & 5 & 100 & & \multirow{4}{*}{$\begin{array}{c}\text { Feldspar } \\
\text { Quartz } \\
\text { Feldspar }\end{array}$} \\
\hline IRSL at $50^{\circ} \mathrm{C}$ & U340 & 5 & 100 & $\operatorname{IRSL}_{50} L_{x}$ & \\
\hline $\mathrm{OSL}$ at $125^{\circ} \mathrm{C}$ & U340 & 5 & 100 & $\begin{array}{c}\mathrm{OSL}_{125} L_{x} \\
\text { post-IR }\end{array}$ & \\
\hline IRSL at $225^{\circ} \mathrm{C}$ & U340 & 5 & 100 & $\operatorname{IRSL}_{225} L_{x}$ & \\
\hline \multicolumn{6}{|l|}{ Test dose 51.75 Gy } \\
\hline Preheat to $250^{\circ} \mathrm{C}$ & U340 & 5 & 100 & & \multirow{4}{*}{$\begin{array}{c}\text { Feldspar } \\
\text { Quartz } \\
\text { Feldspar }\end{array}$} \\
\hline IRSL at $50^{\circ} \mathrm{C}$ & U340 & 5 & 100 & $\operatorname{IRSL}_{50} T_{x}$ & \\
\hline OSL at $125^{\circ} \mathrm{C}$ & U340 & 5 & 100 & $\begin{array}{c}\mathrm{OSL}_{125} T_{x} \\
\text { post-IR }\end{array}$ & \\
\hline IRSL at $225^{\circ} \mathrm{C}$ & U340 & 5 & 100 & $\mathrm{IRSL}_{225} T_{x}$ & \\
\hline \multicolumn{6}{|c|}{ Repeat 5 times } \\
\hline \multicolumn{6}{|c|}{ Experiment D(ii) } \\
\hline Stimulation & Filter & Heating rate $\left({ }^{\circ} \mathrm{C} \mathrm{s}^{-1}\right)$ & Isothermal hold (s) & Signal & Target mineral \\
\hline \multicolumn{6}{|l|}{$\begin{array}{c}\text { Regenerative dose } \\
51.75 \mathrm{~Gy}\end{array}$} \\
\hline Preheat to $250^{\circ} \mathrm{C}$ & BG39 + BG3 & 5 & 100 & & \multirow{4}{*}{$\begin{array}{c}\text { Feldspar } \\
\text { Quartz } \\
\text { Feldspar }\end{array}$} \\
\hline IRSL at $50^{\circ} \mathrm{C}$ & BG39 + BG3 & 5 & 100 & $\mathrm{IRSL}_{50} L_{x}$ & \\
\hline $\mathrm{OSL}$ at $125^{\circ} \mathrm{C}$ & U340 & 5 & 100 & $\begin{array}{c}\mathrm{OSL}_{125} L_{x} \\
\text { post-IR }\end{array}$ & \\
\hline IRSL at $225^{\circ} \mathrm{C}$ & BG39 + BG3 & 5 & 100 & $\operatorname{IRSL}_{225} L_{x}$ & \\
\hline \multicolumn{6}{|l|}{ Test dose 51.75 Gy } \\
\hline Preheat to $250^{\circ} \mathrm{C}$ & BG39 + BG3 & 5 & 100 & & \multirow{4}{*}{$\begin{array}{c}\text { Feldspar } \\
\text { Quartz } \\
\text { Feldspar }\end{array}$} \\
\hline IRSL at $50^{\circ} \mathrm{C}$ & BG39 + BG3 & 5 & 100 & $\operatorname{IRSL}_{50} T_{x}$ & \\
\hline $\mathrm{OSL}$ at $125^{\circ} \mathrm{C}$ & U340 & 5 & 100 & $\begin{array}{l}\mathrm{OSL}_{125} T_{x} \\
\text { post-IR }\end{array}$ & \\
\hline IRSL at $225^{\circ} \mathrm{C}$ & $\mathrm{BG} 39+\mathrm{BG} 3$ & 5 & 100 & $\operatorname{IRSL}_{225} T_{x}$ & \\
\hline \multicolumn{6}{|c|}{ Repeat 5 times } \\
\hline \multicolumn{6}{|c|}{ Experiment D(iii) } \\
\hline Stimulation & Filter & Heating rate $\left({ }^{\circ} \mathrm{C} \mathrm{s}^{-1}\right)$ & Isothermal hold (s) & Signal & Target mineral \\
\hline \multicolumn{6}{|l|}{$\begin{array}{l}\text { Regenerative dose } \\
51.75 \mathrm{~Gy}\end{array}$} \\
\hline Preheat to $250^{\circ} \mathrm{C}$ & BG39 + BG3 & 5 & 100 & & \multirow{4}{*}{$\begin{array}{c}\text { Feldspar } \\
\text { Quartz } \\
\text { Feldspar }\end{array}$} \\
\hline IRSL at $50^{\circ} \mathrm{C}$ & BG39 + BG3 & 5 & 100 & $\operatorname{IRSL}_{50} L_{x}$ & \\
\hline IRSL at $225^{\circ} \mathrm{C}$ & BG39 + BG3 & 5 & 100 & $\mathrm{OSL}_{125} L_{x}$ & \\
\hline OSL at $125^{\circ} \mathrm{C}$ & U340 & 5 & 100 & $\operatorname{IRSL}_{225} L_{x}$ & \\
\hline \multicolumn{6}{|l|}{ Test dose 51.75 Gy } \\
\hline Preheat to $250^{\circ} \mathrm{C}$ & BG39 + BG3 & 5 & 100 & & \\
\hline IRSL at $50^{\circ} \mathrm{C}$ & BG39 + BG3 & 5 & 100 & $\mathrm{IRSL}_{50} T_{x}$ & Feldspar \\
\hline IRSL at $225^{\circ} \mathrm{C}$ & BG39 + BG3 & 5 & 100 & $\mathrm{OSL}_{125} T_{x}$ & Quartz \\
\hline $\mathrm{OSL}$ at $125^{\circ} \mathrm{C}$ & U340 & 5 & 100 & $\begin{array}{l}\text { post-IR } \\
\text { IRSL }_{225} T_{x}\end{array}$ & Feldspar \\
\hline
\end{tabular}




\section{This manuscript is a pre-print and has been submitted for publication in Quaternary Geochronology}

978 Table S4: Measurement protocol for the three parts of Experiment D.

979

\begin{tabular}{|c|c|c|c|c|c|c|}
\hline \multirow[t]{3}{*}{$\begin{array}{c}\text { Protocol } \\
\text { applied }\end{array}$} & \multicolumn{3}{|c|}{ Experiment Ai } & \multicolumn{3}{|c|}{ Experiment Biii } \\
\hline & \multicolumn{6}{|c|}{$\mathrm{IRSL}_{50}$} \\
\hline & $\begin{array}{c}\mu \\
\left(\mathrm{mm}^{-1}\right)\end{array}$ & $\begin{array}{l}\overline{\sigma \varphi_{0}} \\
\left(\mathrm{a}^{-1}\right)\end{array}$ & $\begin{array}{c}\text { Exposure time } \\
\text { (a) }\end{array}$ & $\begin{array}{c}\mu \\
\left(\mathrm{mm}^{-1}\right)\end{array}$ & $\begin{array}{l}\overline{\sigma \varphi_{0}} \\
\left(\mathrm{a}^{-1}\right)\end{array}$ & $\begin{array}{c}\text { Exposure time } \\
\text { (a) }\end{array}$ \\
\hline Median & 2.16 & 404.32 & 2.15 & 1.19 & 12.65 & 2.94 \\
\hline$+1 \mathrm{SD}$ & 2.94 & 5903.80 & 2.91 & 1.91 & 57.44 & 3.18 \\
\hline$-1 \mathrm{SD}$ & 1.20 & 54.21 & 1.77 & 1.00 & 4.61 & 2.69 \\
\hline$+2 \mathrm{SD}$ & 3.32 & 11540.93 & 3.29 & 2.64 & 260.91 & 3.35 \\
\hline \multirow[t]{3}{*}{$-2 \mathrm{SD}$} & 0.81 & 7.25 & 1.39 & 0.64 & 2.78 & 2.45 \\
\hline & \multicolumn{6}{|c|}{$\mathrm{OSL}_{125}$} \\
\hline & $\begin{array}{c}\mu \\
\left(\mathrm{mm}^{-1}\right)\end{array}$ & $\begin{array}{l}\overline{\sigma \varphi_{0}} \\
\left(\mathrm{a}^{-1}\right)\end{array}$ & $\begin{array}{l}\text { Exposure time } \\
\text { (a) }\end{array}$ & $\begin{array}{c}\mu \\
\left(\mathrm{mm}^{-1}\right)\end{array}$ & $\begin{array}{l}\overline{\sigma \varphi_{0}} \\
\left(\mathrm{a}^{-1}\right)\end{array}$ & $\begin{array}{l}\text { Exposure time } \\
\text { (a) }\end{array}$ \\
\hline Median & 1.68 & 23.06 & 0.67 & 1.70 & 10.17 & 3.36 \\
\hline$+1 \mathrm{SD}$ & 2.79 & 568.83 & 0.76 & 2.81 & 43.95 & 4.01 \\
\hline$-1 \mathrm{SD}$ & 0.94 & 4.64 & 0.56 & 1.34 & 4.89 & 3.03 \\
\hline$+2 \mathrm{SD}$ & 3.35 & 2825.35 & 0.78 & 3.36 & 91.39 & 4.33 \\
\hline \multirow[t]{3}{*}{$-2 \mathrm{SD}$} & 0.75 & 2.72 & 0.47 & 0.97 & 2.35 & 2.38 \\
\hline & \multicolumn{6}{|c|}{ post-IR IRSL $_{125}$} \\
\hline & $\begin{array}{c}\mu \\
\left(\mathrm{mm}^{-1}\right)\end{array}$ & $\begin{array}{l}\overline{\sigma \varphi_{0}} \\
\left(\mathrm{a}^{-1}\right)\end{array}$ & $\begin{array}{l}\text { Exposure time } \\
\text { (a) }\end{array}$ & $\begin{array}{c}\mu \\
\left(\mathrm{mm}^{-1}\right)\end{array}$ & $\begin{array}{l}\overline{\sigma \varphi_{0}} \\
\left(\mathrm{a}^{-1}\right)\end{array}$ & $\begin{array}{l}\text { Exposure time } \\
\text { (a) }\end{array}$ \\
\hline Median & 2.34 & 1.14 & 6.48 & 1.60 & 4.90 & 3.42 \\
\hline$+1 \mathrm{SD}$ & 3.51 & 26.21 & 7.53 & 2.75 & 9.84 & 4.05 \\
\hline$-1 \mathrm{SD}$ & 1.17 & 0.05 & 5.42 & 1.02 & 2.44 & 2.80 \\
\hline$+2 \mathrm{SD}$ & 3.71 & 125.89 & 8.23 & 3.52 & 39.64 & 4.45 \\
\hline$-2 \mathrm{SD}$ & 0.39 & 0.00 & 4.37 & 0.83 & 1.22 & 2.39 \\
\hline
\end{tabular}

980

981 Table S7: Unknown parameter and exposure age results from the modelling.

982 
This manuscript is a pre-print and has been submitted for publication in Quaternary Geochronology

$\operatorname{IRSL}_{50}$

Position 1 (10 $\mathrm{mm}$ diameter slice)

\begin{tabular}{|c|c|c|c|c|c|c|c|c|c|c|c|c|}
\hline & \multicolumn{3}{|c|}{ Experiment Bi- U430 filter } & \multicolumn{3}{|c|}{ Experiment Bii- BG39+ BG3 } & \multicolumn{3}{|c|}{ Experiment Di- U430 filter } & \multicolumn{3}{|c|}{ Experiment Dii- BG39 + BG3 } \\
\hline & Signal & BG & $\mathrm{Lx}$ & Signal & BG & $\mathrm{Lx}$ & Signal & $\mathrm{BG}$ & $\mathrm{Lx}$ & Signal & BG & $\mathrm{Lx}$ \\
\hline Cycle 1 & $6.5 \mathrm{E}+04$ & $1.4 \mathrm{E}+03$ & $6.3 \mathrm{E}+04$ & $5.6 \mathrm{E}+04$ & $2.6 \mathrm{E}+03$ & $5.4 \mathrm{E}+04$ & $3.8 \mathrm{E}+04$ & $8.9 \mathrm{E}+02$ & $3.7 \mathrm{E}+04$ & $4.0 \mathrm{E}+04$ & $2.5 \mathrm{E}+03$ & $3.8 \mathrm{E}+04$ \\
\hline Cycle 2 & $6.2 \mathrm{E}+04$ & $1.3 \mathrm{E}+03$ & $6.1 \mathrm{E}+04$ & $5.6 \mathrm{E}+04$ & $2.6 \mathrm{E}+03$ & $5.4 \mathrm{E}+04$ & $2.9 \mathrm{E}+04$ & $7.8 \mathrm{E}+02$ & $2.8 \mathrm{E}+04$ & $4.0 \mathrm{E}+04$ & $2.5 \mathrm{E}+03$ & $3.8 \mathrm{E}+04$ \\
\hline Cycle 3 & $6.1 \mathrm{E}+04$ & $1.3 \mathrm{E}+03$ & $6.0 \mathrm{E}+04$ & $5.6 \mathrm{E}+04$ & $2.6 \mathrm{E}+03$ & $5.3 \mathrm{E}+04$ & $2.8 \mathrm{E}+04$ & $7.7 \mathrm{E}+02$ & $2.7 \mathrm{E}+04$ & $4.0 \mathrm{E}+04$ & $2.5 \mathrm{E}+03$ & $3.8 \mathrm{E}+04$ \\
\hline Cycle 4 & $6.1 \mathrm{E}+04$ & $1.3 \mathrm{E}+03$ & $6.0 \mathrm{E}+04$ & $5.6 \mathrm{E}+04$ & $2.6 \mathrm{E}+03$ & $5.3 \mathrm{E}+04$ & $2.8 \mathrm{E}+04$ & $7.6 \mathrm{E}+02$ & $2.7 \mathrm{E}+04$ & $4.0 \mathrm{E}+04$ & $2.5 \mathrm{E}+03$ & $3.8 \mathrm{E}+04$ \\
\hline Cycle 5 & $6.1 \mathrm{E}+04$ & $1.3 \mathrm{E}+03$ & $5.9 \mathrm{E}+04$ & $5.6 \mathrm{E}+04$ & $2.5 \mathrm{E}+03$ & $5.3 \mathrm{E}+04$ & $2.7 \mathrm{E}+04$ & $7.3 \mathrm{E}+02$ & $2.6 \mathrm{E}+04$ & $4.0 \mathrm{E}+04$ & $2.5 \mathrm{E}+03$ & $3.7 \mathrm{E}+04$ \\
\hline $\begin{array}{l}\text { Average } \\
\text { intensity }\end{array}$ & & & $6.1 \mathrm{E}+04$ & & & $5.3 \mathrm{E}+04$ & & & $2.9 \mathrm{E}+04$ & & & $3.8 \mathrm{E}+04$ \\
\hline
\end{tabular}
$9 \overline{83}$

post-IR IRSL 225

Position 1 (10 $\mathrm{mm}$ diameter slice)

\begin{tabular}{|c|c|c|c|c|c|c|c|c|c|c|c|c|}
\hline & \multicolumn{3}{|c|}{ Experiment Bi- U430 filter } & \multicolumn{3}{|c|}{ Experiment Bii- BG39 + BG3 } & \multicolumn{3}{|c|}{ Experiment Di- U430 filter } & \multicolumn{3}{|c|}{ Experiment Dii- BG39 + BG3 } \\
\hline & Signal & BG & $\mathrm{Lx}$ & Signal & $\mathrm{BG}$ & $\mathrm{Lx}$ & Signal & BG & $\mathrm{Lx}$ & Signal & $\mathrm{BG}$ & $\mathrm{Lx}$ \\
\hline Cycle 1 & $6.0 \mathrm{E}+03$ & $5.2 \mathrm{E}+03$ & $9.1 \mathrm{E}+02$ & $3.1 \mathrm{E}+04$ & $2.8 \mathrm{E}+04$ & $3.6 \mathrm{E}+03$ & $5.5 \mathrm{E}+03$ & $4.0 \mathrm{E}+03$ & $1.5 \mathrm{E}+03$ & $3.4 \mathrm{E}+04$ & $2.9 \mathrm{E}+04$ & $5.5 \mathrm{E}+03$ \\
\hline Cycle 2 & $5.2 \mathrm{E}+03$ & $4.5 \mathrm{E}+03$ & $6.5 \mathrm{E}+02$ & $3.1 \mathrm{E}+04$ & $2.7 \mathrm{E}+04$ & $3.4 \mathrm{E}+03$ & $3.7 \mathrm{E}+03$ & $2.7 \mathrm{E}+03$ & $9.5 \mathrm{E}+02$ & $3.4 \mathrm{E}+04$ & $2.9 \mathrm{E}+04$ & $5.2 \mathrm{E}+03$ \\
\hline Cycle 3 & $5.4 \mathrm{E}+03$ & $4.4 \mathrm{E}+03$ & $9.9 \mathrm{E}+02$ & $3.1 \mathrm{E}+04$ & $2.7 \mathrm{E}+04$ & $3.3 \mathrm{E}+03$ & $3.5 \mathrm{E}+03$ & $2.5 \mathrm{E}+03$ & $9.4 \mathrm{E}+02$ & $3.4 \mathrm{E}+04$ & $2.9 \mathrm{E}+04$ & $5.2 \mathrm{E}+03$ \\
\hline Cycle 4 & $5.1 \mathrm{E}+03$ & $4.2 \mathrm{E}+03$ & $8.6 \mathrm{E}+02$ & $3.0 \mathrm{E}+04$ & $2.7 \mathrm{E}+04$ & $3.2 \mathrm{E}+03$ & $3.4 \mathrm{E}+03$ & $2.5 \mathrm{E}+03$ & $9.0 \mathrm{E}+02$ & $3.4 \mathrm{E}+04$ & $2.9 \mathrm{E}+04$ & $5.3 \mathrm{E}+03$ \\
\hline Cycle 5 & $4.9 \mathrm{E}+03$ & $4.3 \mathrm{E}+03$ & $6.5 \mathrm{E}+02$ & $3.1 \mathrm{E}+04$ & $2.7 \mathrm{E}+04$ & $3.7 \mathrm{E}+03$ & $3.4 \mathrm{E}+03$ & $2.4 \mathrm{E}+03$ & $1.0 \mathrm{E}+03$ & $3.4 \mathrm{E}+04$ & $2.9 \mathrm{E}+04$ & $5.1 \mathrm{E}+03$ \\
\hline $\begin{array}{l}\text { Average } \\
\text { intensity }\end{array}$ & & & $8.1 \mathrm{E}+02$ & & & $3.5 \mathrm{E}+03$ & & & $1.1 \mathrm{E}+03$ & & & $5.3 \mathrm{E}+03$ \\
\hline
\end{tabular}

985 Table S5: Lx signal intensities for a $10 \mathrm{~mm}$ diameter slice across parts (i) and (ii) of Experiments B and D for both the IRSL 50 and post-IR IRSL 225 signals. 
This manuscript is a pre-print and has been submitted for publication in Quaternary Geochronology

$\operatorname{IRSL}_{50}$

Position 11 (5 mm diameter slice)

\begin{tabular}{|c|c|c|c|c|c|c|c|c|c|c|c|c|}
\hline & \multicolumn{3}{|c|}{ Experiment Bi- U430 filter } & \multicolumn{3}{|c|}{ Experiment Bii- BG39+ BG3 } & \multicolumn{3}{|c|}{ Experiment Di- U430 filter } & \multicolumn{3}{|c|}{ Experiment Dii- BG39 + BG3 } \\
\hline & Signal & $\mathrm{BG}$ & $\mathrm{Lx}$ & Signal & $\mathrm{BG}$ & $\mathrm{Lx}$ & Signal & $\mathrm{BG}$ & $\mathrm{Lx}$ & Signal & $\mathrm{BG}$ & $\mathrm{Lx}$ \\
\hline Cycle 1 & $3.5 \mathrm{E}+03$ & $2.2 \mathrm{E}+02$ & $3.3 \mathrm{E}+03$ & $9.5 \mathrm{E}+03$ & $2.8 \mathrm{E}+03$ & $6.7 \mathrm{E}+03$ & $1.4 \mathrm{E}+03$ & $2.8 \mathrm{E}+02$ & $1.1 \mathrm{E}+03$ & $5.9 \mathrm{E}+03$ & $2.5 \mathrm{E}+03$ & $3.4 \mathrm{E}+03$ \\
\hline Cycle 2 & $3.4 \mathrm{E}+03$ & $2.4 \mathrm{E}+02$ & $3.2 \mathrm{E}+03$ & $9.7 \mathrm{E}+03$ & $2.9 \mathrm{E}+03$ & $6.8 \mathrm{E}+03$ & $1.3 \mathrm{E}+03$ & $2.6 \mathrm{E}+02$ & $1.0 \mathrm{E}+03$ & $5.8 \mathrm{E}+03$ & $2.5 \mathrm{E}+03$ & $3.3 \mathrm{E}+03$ \\
\hline Cycle 3 & $3.4 \mathrm{E}+03$ & $2.1 \mathrm{E}+02$ & $3.2 \mathrm{E}+03$ & $9.5 \mathrm{E}+03$ & $2.9 \mathrm{E}+03$ & $6.6 \mathrm{E}+03$ & $1.2 \mathrm{E}+03$ & $2.7 \mathrm{E}+02$ & $9.4 \mathrm{E}+02$ & $5.8 \mathrm{E}+03$ & $2.6 \mathrm{E}+03$ & $3.2 \mathrm{E}+03$ \\
\hline Cycle 4 & $3.2 \mathrm{E}+03$ & $1.8 \mathrm{E}+02$ & $3.0 \mathrm{E}+03$ & $9.3 \mathrm{E}+03$ & $2.8 \mathrm{E}+03$ & $6.5 \mathrm{E}+03$ & $1.3 \mathrm{E}+03$ & $2.8 \mathrm{E}+02$ & $9.8 \mathrm{E}+02$ & $5.9 \mathrm{E}+03$ & $2.5 \mathrm{E}+03$ & $3.4 \mathrm{E}+03$ \\
\hline Cycle 5 & $3.0 \mathrm{E}+03$ & $2.1 \mathrm{E}+02$ & $2.8 \mathrm{E}+03$ & $9.2 \mathrm{E}+03$ & $2.8 \mathrm{E}+03$ & $6.4 \mathrm{E}+03$ & $1.1 \mathrm{E}+03$ & $2.6 \mathrm{E}+02$ & $8.9 \mathrm{E}+02$ & $5.7 \mathrm{E}+03$ & $2.5 \mathrm{E}+03$ & $3.2 \mathrm{E}+03$ \\
\hline $\begin{array}{l}\text { Average } \\
\text { intensity }\end{array}$ & & & $3.1 \mathrm{E}+03$ & & & $6.6 \mathrm{E}+03$ & & & $9.9 \mathrm{E}+02$ & & & $3.3 \mathrm{E}+03$ \\
\hline
\end{tabular}
$9 \overline{87}$

post-IR IRSL 225

Position 11 (5 mm diameter slice)

\begin{tabular}{|c|c|c|c|c|c|c|c|c|c|c|c|c|}
\hline & \multicolumn{3}{|c|}{ Experiment Bi- U430 filter } & \multicolumn{3}{|c|}{ Experiment Bii- BG39+ BG3 } & \multicolumn{3}{|c|}{ Experiment Di- U430 filter } & \multicolumn{3}{|c|}{ Experiment Dii- BG39+ BG3 } \\
\hline & Signal & BG & $\mathrm{Lx}$ & Signal & BG & $\mathrm{Lx}$ & Signal & BG & $\mathrm{Lx}$ & Signal & BG & $\mathrm{Lx}$ \\
\hline Cycle 1 & $1.4 \mathrm{E}+03$ & $7.8 \mathrm{E}+02$ & $6.2 \mathrm{E}+02$ & $7.8 \mathrm{E}+03$ & $5.4 \mathrm{E}+03$ & $2.4 \mathrm{E}+03$ & $8.3 \mathrm{E}+02$ & $5.1 \mathrm{E}+02$ & $3.3 \mathrm{E}+02$ & $7.4 \mathrm{E}+03$ & $5.6 \mathrm{E}+03$ & $1.8 \mathrm{E}+03$ \\
\hline Cycle 2 & $1.3 \mathrm{E}+03$ & $7.6 \mathrm{E}+02$ & $5.3 \mathrm{E}+02$ & $7.6 \mathrm{E}+03$ & $5.5 \mathrm{E}+03$ & $2.2 \mathrm{E}+03$ & $7.9 \mathrm{E}+02$ & $4.9 \mathrm{E}+02$ & $3.0 \mathrm{E}+02$ & $7.3 \mathrm{E}+03$ & $5.5 \mathrm{E}+03$ & $1.8 \mathrm{E}+03$ \\
\hline Cycle 3 & $1.4 \mathrm{E}+03$ & $7.6 \mathrm{E}+02$ & $6.4 \mathrm{E}+02$ & $7.7 \mathrm{E}+03$ & $5.5 \mathrm{E}+03$ & $2.2 \mathrm{E}+03$ & $7.5 \mathrm{E}+02$ & $5.3 \mathrm{E}+02$ & $2.1 \mathrm{E}+02$ & $7.3 \mathrm{E}+03$ & $5.4 \mathrm{E}+03$ & $1.9 \mathrm{E}+03$ \\
\hline Cycle 4 & $1.4 \mathrm{E}+03$ & $7.4 \mathrm{E}+02$ & $6.5 \mathrm{E}+02$ & $7.7 \mathrm{E}+03$ & $5.5 \mathrm{E}+03$ & $2.2 \mathrm{E}+03$ & $6.9 \mathrm{E}+02$ & $5.2 \mathrm{E}+02$ & $1.8 \mathrm{E}+02$ & $7.2 \mathrm{E}+03$ & $5.4 \mathrm{E}+03$ & $1.9 \mathrm{E}+03$ \\
\hline Cycle 5 & $1.3 \mathrm{E}+03$ & $7.2 \mathrm{E}+02$ & $6.0 \mathrm{E}+02$ & $7.6 \mathrm{E}+03$ & $5.4 \mathrm{E}+03$ & $2.2 \mathrm{E}+03$ & $7.4 \mathrm{E}+02$ & $5.2 \mathrm{E}+02$ & $2.2 \mathrm{E}+02$ & $7.1 \mathrm{E}+03$ & $5.4 \mathrm{E}+03$ & $1.7 \mathrm{E}+03$ \\
\hline $\begin{array}{l}\text { Average } \\
\text { intensity }\end{array}$ & & & $6.1 \mathrm{E}+02$ & & & $2.2 \mathrm{E}+03$ & & & $2.5 \mathrm{E}+02$ & & & $1.8 \mathrm{E}+03$ \\
\hline
\end{tabular}

989 Table S6: Lx signal intensities for a $5 \mathrm{~mm}$ diameter slice across parts (i) and (ii) of Experiments B and D for both the IRSL 50 and post-IR IRSL 225 signals.

990 